\title{
Los ADPIC y el TLCAN en la industria farmacéutica mexicana: Un análisis TradeCAN*
}

\author{
Rodrigo A. Guerrero Castro** y Roberto Gutiérrez R.***
}

\section{RESUMEN}

El trabajo muestra el deterioro de la industria farmacéutica mexicana, lo mismo de insumos que de productos finales, en los ámbitos comercial, de competitividad y de actividad inventiva - producción de conocimiento patentado - a principios de la década de los noventa. Dicho deterioro se vincula con la apertura externa de la economía mexicana, iniciada en 1985 con el desmantelamiento unilateral de su aparato arancelario y su ingreso al GATT, un año después, y avanza en 1991 con la aceptación de los acuerdos comerciales de carácter sectorial conocidos como ADPIC y la instrumentación de la Ley de Fomento y Protección de la Propiedad Industrial, así como la puesta en operación del TLCAN, en 1994. Para demostrar su hipótesis recurre, como principal herramienta, a la versión más reciente del software desarrollado por la CEPAL para analizar la competitividad de las naciones, conocido como TradeCAN, a cinco dígitos de la CUCI. Asimismo, evidencia el crecimiento del comercio de las empresas farmacéuticas transnacionales que operan en México; cuantifica el comercio farmacéutico intraindustrial del país, que ha tendido a desacelerarse, y presenta una síntesis de los puntos de vista de diferentes expertos de la industria.

Palabras clave: industria farmacéutica, comercio, tecnología, propiedad industrial, ADPIC. Clasificación JEL: F14.

\section{Abstract}

The work shows the deterioration of the Mexican pharmaceutical industry ever since de early nineties at the commercial, competitive and inventive activity levels, considering both inputs and final products. Such a deterioration is linked to the external opening of the Mexican economy, which began in 1985 with the unilateral dismantling of tariff barriers and the annexing of Mexico to GATT, a year later, and advanced in 1991 with the acceptance of sector-specific trade agreements known as TRIP's and the implementation of the Law on the Promotion and Protection of Industrial Property, and finally the instrumentation of NAFTA, in 1994. To prove its hypothesis, the essay takes as a main tool the latest version of the software developed by ECLAC for analyzing the competitiveness of nations, known as TradeCAN, at five-digit SITC. It also suggests the growth of intra-firm trade of multinational pharmaceutical companies operating in Mexico; quantifies intra-industry trade of Mexico, which has slowed down, and presents a synthesis of views from different industry experts.

Key words: pharmaceutical industry, trade, technology, industrial property, TRIP's.

Classification JEL: F14.

* Fecha de recepción: 06/05/2011. Fecha de aceptación: 14/09/2011. La presente es una versión revisada por ambos autores para el ámbito comercial del documento de Guerrero (2010), del que Gutiérrez fungió como asesor. Se agradecen los pertinentes comentarios de dos dictaminadores anónimos, quienes no se comprometen con los errores finales, que son responsabilidad solidaria de los autores.

** Egresado de la maestría en Economía y Gestión de la Innovación (UAM-Xochimilco). Correo electrónico: roarmando.gc@gmail.com

*** Profesor-investigador del Departamento de Economía de la UAM-Iztapalapa. Correo electrónico: robertogtz@yahoo.com 


\section{INTRODUCCIÓN}

En el nivel macroeconómico, el ingreso de México al Acuerdo General sobre Aranceles Aduaneros y Comercio (GATT) y la puesta en operación del Tratado de Libre Comercio de América del Norte (TLCAN) en 1986 y 1994, respectivamente, impulsaron al sector externo de la economía mexicana. El coeficiente de apertura de ésta (exportaciones más importaciones de bienes y servicios sobre producto interno bruto, PIB) pasó de 31\% en 1990 a 65\% en 2000 (Banxico, 2011; INEGI, 2011). Ello propició una más alta tasa de crecimiento del producto y del empleo. Empero, ese círculo virtuoso se ha ido desvaneciendo a partir de la recesión estadounidense de 2001 ("burbuja tecnológica") y del ingreso de China a la Organización Mundial de Comercio (OMC), en ese mismo año.

A nivel microeconómico - empresa, rama, industria, región- el TLCAN permitió que se consolidara un grupo importante de sectores ganadores; pero también hubo perdedores. No sólo el sector agropecuario, las industrias textil y de la confección, la mueblera y de juguetes, y las empresas de tamaño micro y pequeño se vieron perjudicadas. Zonas metropolitanas completas como las de Tijuana, en Baja California; Ciudad Juárez, en Chihuahua, y Matamoros, en Tamaulipas, han enfrentado problemas de descomposición social asociados al desempleo que causó la contracción de la industria maquiladora de exportación, con consecuencias en otras áreas de dichos estados y a otras regiones del país.

Por lo que respecta a la industria farmacéutica mexicana, otra perdedora del TLCAN, redujo su crecimiento potencial, sus posibilidades de generar empleos y su velocidad de reacción frente a diversos padecimientos que aquejan al país, tanto por razones de transición epidemiológica, que obliga a prestar una atención creciente a afecciones como el VIH-sida, diabetes y tumores malignos, como por la aparición de epidemias desconocidas (virus AH1N1) y por el potencial regreso de otras que se suponían superadas - cólera, dengue, paludismo, mal de Chagas - o ajenas al país - virus del Nilo-. En esto mucho tiene que ver la globalización de los mercados de bienes y servicios, de la que el TLCAN es una expresión.

En el entorno descrito, el trabajo pretende mostrar el deterioro de la industria farmacéutica nacional en los ámbitos comercial y de actividad inventiva, vinculados en lo fundamental a la firma del TLCAN y a la aceptación de acuerdos previos a dicha acción, conocidos como Aspectos de los Derechos de Propiedad Intelectual Relacionados con el Comercio (ADPIC), o Trade Related Aspects of Intellectual Property Rights (TRIP's). Para ello se analiza particularmente la com- 
petitividad del sector farmacéutico de México, y se exploran de manera tangencial la de Estados Unidos y Canadá antes y a partir de la puesta en operación del TLCAN mediante una herramienta muy versátil pero subexplotada en las escuelas de economía y comercio de América Latina, así como en las oficinas especializadas: el Competitive Analysis of Nations (TradeCAN). ${ }^{1}$ Dicho software, desarrollado por la Comisión Económica para América Latina y el Caribe (CEPAL), mide la competitividad de las naciones de manera individual o regional con una serie de indicadores y un nivel de desagregación tal que permiten al analista llegar a conclusiones importantes respecto a la capacidad que tienen, o que han desarrollado, las distintas ramas y sectores de la economía para sacar provecho de la política de apertura comercial, instrumentada en la región a partir de mediados de los años ochenta.

En el proceso de análisis se abordan dos elementos de política industrial, comercial y tecnológica que se relacionan directamente con el comercio exterior y el desarrollo tecnológico. El primero se refiere a las consecuencias que para la industria farmacéutica de México tuvo la entrada en vigor de los ADPIC, los cuales se implantaron inclusive antes de la puesta en operación del TLCAN, por lo que la jerga especializada los conoce como pre ADPIC. El segundo tiene que ver con los derechos de propiedad industrial (DPI), que se modificaron en consecuencia con los pre ADPIC, a partir de 1991, lo que refleja la función pasiva que las instituciones públicas del país asumieron respecto a la industria farmacéutica mexicana, en comparación con el activismo de que fueron objeto sus contrapartes de Estados Unidos y Canadá. ${ }^{2}$ Esto porque al entrar en vigor los ADPIC, al transformarse el GATT en Organización Mundial de Comercio (OMC) y modificarse los DPI mediante la puesta en operación, en junio de 1991, de la Ley de

\footnotetext{
${ }^{1}$ La desagregación del TradecAN en la industria farmacéutica permite analizar lo mismo insumos que productos finales, utilizando la Clasificación Uniforme para el Comercio Internacional, Revisión 2 (CUCI 2) (TradecAN, 2009).

${ }^{2} \mathrm{La}$ industria farmacéutica internacional ha sido promotora de grandes cambios legislativos a favor de la inversión extranjera directa (IED), incluyendo los DPI. En México, dichos cambios se adoptaron antes de lo planteado en la OMC, que sustituyó al GATT en 1995. De ahí el concepto de pre ADPIC (Aboites y Soria, 2008). En 1987, México reformó su Ley de Invenciones y Marcas y derogó el reglamento de ésta. Tales ajustes parecieron insuficientes a sus futuros socios comerciales en el TLCAN, Canadá y Estados Unidos, que insistieron en que la legislación mexicana debía fortalecer el DPI. Por tanto, el 27 de junio de 1991, antes de ratificar el TLCAN, el gobierno federal promulgó la Ley de Fomento y Protección de la Propiedad Industrial (Moïse y Docteur, 2007). Por primera vez desde la Ley de Comercio de 1974, la propiedad intelectual se integró al marco institucional del sistema comercial internacional, reflejando la voluntad de Estados Unidos de vincular sus relaciones comerciales con la protección de la propiedad intelectual (Roffe, 2008).
} 
Fomento y Protección de la Propiedad Industrial, la industria se consolidó regionalmente pero no nacionalmente.

En lo internacional el tema de los DPI y su relación con el ámbito comercial está muy vinculado con el ritmo de la economía y la actividad inventiva de las empresas estadounidenses. ${ }^{3}$ Así lo corrobora la siguiente cita: “... [en] 1995, $63 \%$ de las patentes registradas [en Estados Unidos] fueron hechas por estadounidenses, $25 \%$ por europeos, $7 \%$ por japoneses y $5 \%$ por el resto del mundo. Entre 1980 y 1995, las empresas estadounidenses fueron capaces de globalizar su producción, lanzando al mercado europeo y japonés sus nuevos productos a una tasa de más del doble de sus rivales europeas. De hecho, los estadounidenses tienen el $40 \%$ del mercado mundial de medicamentos" (Corona y Jiménez, 2003, p. 504).

Es decir que, conforme aumentaron las relaciones comerciales entre los países de América del Norte, se incrementó la presencia de las patentes extranjeras de productos farmacéuticos en México, lo que implica que éstas dejaron de ser explotadas productivamente para transformarse en vehículos de beneficio comercial por la vía de la importación. Con ello se coartó a la industria la posibilidad de transferir y adaptar tecnología a partir de la imitación de productos de frontera y la consecuente generación de procesos de aprendizaje, ${ }^{4}$ como se hacía en el marco del modelo de industrialización vía sustitución de importaciones (ISI), vigente hasta principios de los años ochenta. ${ }^{5}$

Como se aprecia, los ADPIC y el TLCAN arrojan para la industria resultados totalmente opuestos a los que se perseguirían en un enfoque de búsqueda de competitividad. A la luz de los resultados hasta 2010, dicha industria ha experimentado una regresión de 20 años, que se evidencia mediante las cinco secciones que integran este trabajo: saldo comercial de México, lo mismo de insumos que de productos finales, haciendo referencia a los otros dos países miembros del

3 "El paradigma creado por la biotecnología (estrechamente vinculado con el desarrollo de la industria farmacéutica) no sólo ha generado nuevas posibilidades tecnológicas ...; también ha venido transformando los mercados y las expectativas de los agentes económicos y políticos: ha movido a corredores de bolsa y directivos de industria, ha cambiado reglas y convenciones establecidas" (Corona y Jiménez, 2003, p. 499). Es este nuevo paradigma el que impulsó, a través de las empresas estadounidenses, el tema de los DPI a la agenda del GATT y la OMC.

4 “... el efecto de impulsar las capacidades tecnológicas locales, específicamente en el subsector de farmoquímicos, tales como el marco legal prevaleciente en las décadas previas a la liberalización comercial, conformó un subsector industrial farmoquímico predominantemente mexicano" (Gonsen y Jasso, 2000).

${ }^{5}$ Para un análisis más profundo respecto a la trayectoria científico-tecnológica de esta industria (véase Corona y Jiménez, 2003). 
TLCAN; comercio intraindustrial (CII) y CII promedio ponderado de México; análisis teórico de la implementación de los ADPIC y de la innovación tecnológica en los países en vías de desarrollo (PVD); efecto de los ADPIC en la concentración inventiva en México; análisis de la competitividad de los tres países miembros del TLCAN a través del TradeCAN, y conclusiones.

\section{SALDO COMERCIAL DE LA BALANZA FARMACÉUTICA MEXICANA}

A continuación se presentan los datos correspondientes a la actividad comercial agregada de la industria farmacéutica mexicana reportados por la Base de Datos del Comercio Exterior de América Latina y el Caribe, Badecel (CEPAL/Badecel, 2010). ${ }^{6}$

Cuadro 1. México: exportaciones (X) e importaciones (M) de insumos y productos finales farmacéuticos de y hacia el mundo (1983-2008)

(Miles de dólares)

\begin{tabular}{|c|c|c|c|c|}
\hline \multirow{2}{*}{ Año } & \multicolumn{2}{|c|}{ Insumos } & \multicolumn{2}{c|}{ Productos finales } \\
\cline { 2 - 5 } & $X$ & $M$ & $X$ & $M$ \\
\hline 1983 & 22839 & 78231 & 24260 & 8692 \\
\hline 1984 & 32466 & 100729 & 21211 & 13870 \\
\hline 1985 & 15662 & 103740 & 16156 & 15657 \\
\hline 1986 & 20196 & 96329 & 50038 & 21924 \\
\hline 1987 & 28617 & 117550 & 22492 & 21367 \\
\hline 1988 & 43793 & 137698 & 27515 & 26615 \\
\hline 1989 & 60447 & 175837 & 77005 & 51080 \\
\hline 1990 & 60372 & 195464 & 28654 & 74972 \\
\hline 1991 & 81905 & 231951 & 38955 & 114316 \\
\hline 1992 & 101768 & 270222 & 117576 & 151628 \\
\hline 1993 & 109528 & 322170 & 126165 & 211733 \\
\hline 1994 & 104487 & 410862 & 193548 & 265184 \\
\hline 1995 & 139046 & 343400 & 260358 & 243518 \\
\hline 1996 & 167000 & 455243 & 387325 & 347698 \\
\hline 1997 & 185530 & 449456 & 455181 & 420249 \\
\hline 1998 & 200266 & 534471 & 516416 & 549490 \\
\hline 1999 & 195678 & 540005 & 587576 & 696013 \\
\hline 2000 & 224710 & 581010 & 655670 & 828840 \\
\hline
\end{tabular}

\footnotetext{
${ }^{6}$ En el anexo estadístico se presenta un cuadro que incluye valores similares a los del cuadro 1 para Canadá y Estados Unidos, además de repetir los de México. Esto permite al lector establecer comparaciones sobre el comercio exterior de insumos y productos finales de la industria farmacéutica - monto y ritmo de exportaciones, importaciones y saldo- en los tres países miembros del TLCAN.
} 
Cuadro 1. México: exportaciones (X) e importaciones (M) de insumos y productos finales farmacéuticos de y hacia el mundo (1983-2008) (Conclusión)

(Miles de dólares)

\begin{tabular}{|c|c|c|c|c|}
\hline \multirow{2}{*}{ Año } & \multicolumn{2}{|c|}{ Insumos } & \multicolumn{2}{c|}{ Productos finales } \\
\cline { 2 - 5 } & $X$ & $M$ & $X$ & $M$ \\
\hline 2001 & 220316 & 545788 & 865313 & 1071976 \\
\hline 2002 & 223937 & 606766 & 947633 & 1253535 \\
\hline 2003 & 244534 & 658910 & 1010679 & 1515236 \\
\hline 2004 & 200460 & 674624 & 1231243 & 1878543 \\
\hline 2005 & 184388 & 750679 & 1218853 & 2078171 \\
\hline 2006 & 173074 & 915949 & 1169271 & 2530749 \\
\hline 2007 & 243589 & 1199084 & 1234180 & 2664617 \\
\hline 2008 & 238281 & 1515947 & 1237303 & 3093800 \\
\hline
\end{tabular}

Fuente: Elaboración propia a partir de CEPAL/Badecel (2010).

En primer lugar destaca el hecho, presentado en la gráfica 1, de que las exportaciones de insumos farmacéuticos no rebasaron en ningún año individual del periodo analizado (1983-2008) la suma de 250 millones de dólares, mientras las importaciones superaron dicho monto a partir de 1992, año en que entraron en operación los pre ADPIC. Ya en 2008 dichas importaciones habían llegado a más de 1500 millones de dólares, lo que quiere decir que durante los 15 primeros años de operación del TLCAN se generó un déficit comercial creciente en este tipo de mercancías, como muestra la línea con valores negativos de la gráfica 1 .

Gráfica 1. Balanza comercial de insumos farmacéuticos de México con el mundo (1983-2008)

(Miles de dólares)

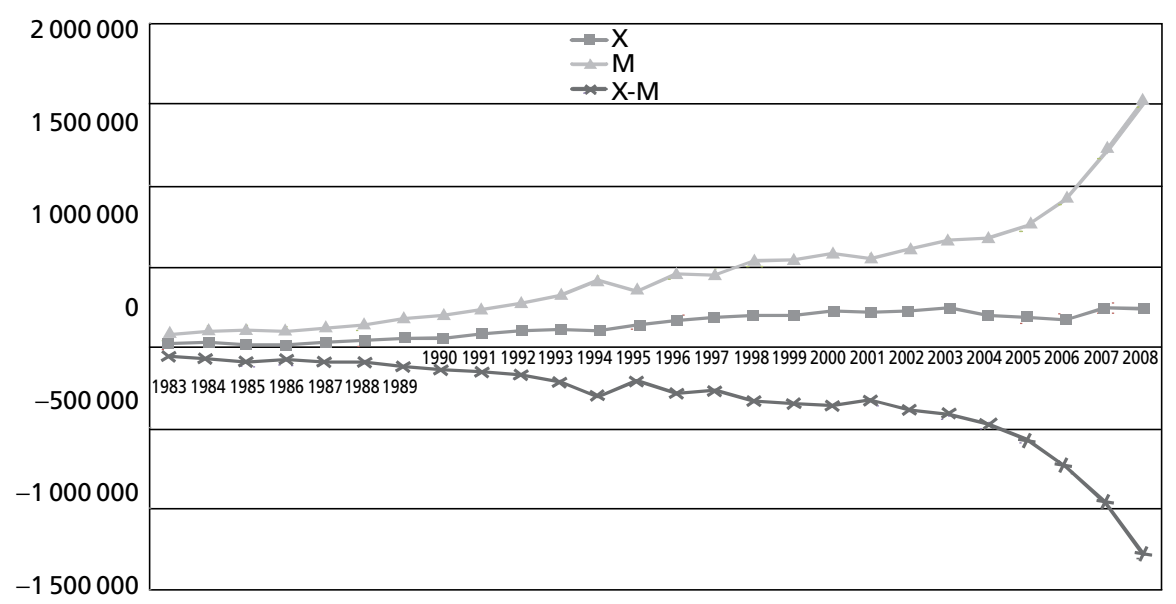

Fuente: Elaboración propia a partir de CEPAL/Badecel (2010). 
En segundo lugar, se observa un acelerado crecimiento, evidenciado en la gráfica 2, tanto de las exportaciones como de las importaciones de productos farmacéuticos de consumo final a partir de 1992, aunque con una evolución más dinámica de la segunda variable que de la primera, lo que se tradujo en una profundización del déficit comercial de dicha actividad (línea con valores negativos de la gráfica). El problema no existía entre 1983 y 1989, en virtud de que la legislación previa a los ADPIC y al TLCAN facultaba a la industria para recurrir a la imitación. En otras palabras, la aceptación de los ADPIC, como requisito para la firma del TLCAN, colocó una camisa de fuerza a la industria farmacéutica mexicana que la llevó en pocos años a una situación de dependencia sin precedentes.

\section{Gráfica 2. Balanza comercial de productos finales farmacéuticos de México con el mundo (1983 - 2008) \\ (Miles de dólares)}

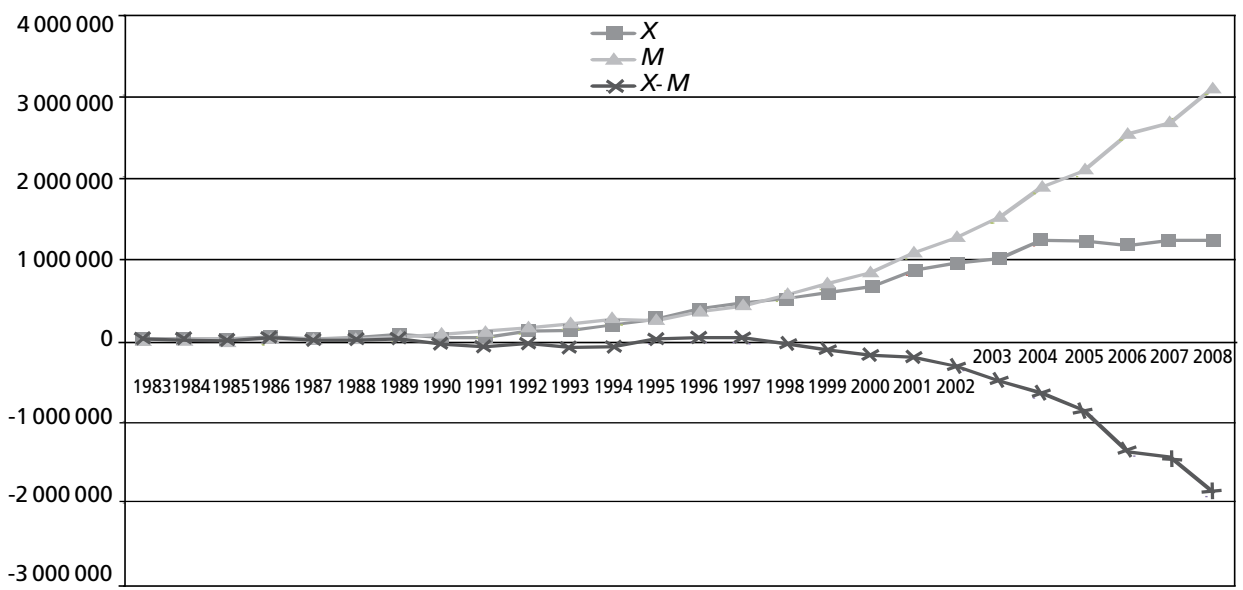

Fuente: Elaboración propia a partir de CEPAL/Badecel (2010).

Si se analiza la evolución tanto de las exportaciones como de las importaciones de insumos y productos a partir de un índice (gráfica 3), es posible observar con mayor claridad el deterioro señalado.

El cuadro 2 separa en dos subperiodos el comportamiento anterior, a fin de demostrar tanto las mayores tasas de crecimiento del comercio de insumos y productos finales como el deterioro que generó la transición de una economía en que apenas se consolidaban en dicha industria los ADPIC y el TLCAN (primer periodo indicado) a otra en que ya operaban plenamente (segundo periodo). 
100 ECONOMÍA: TEORÍA Y PRÁCTICA • Nueva Época, número 35, julio-diciembre 2011

Gráfica 3. México: exportaciones e importaciones de insumos y productos farmacéuticos de y hacia el mundo (Índice de crecimiento,1983=10)

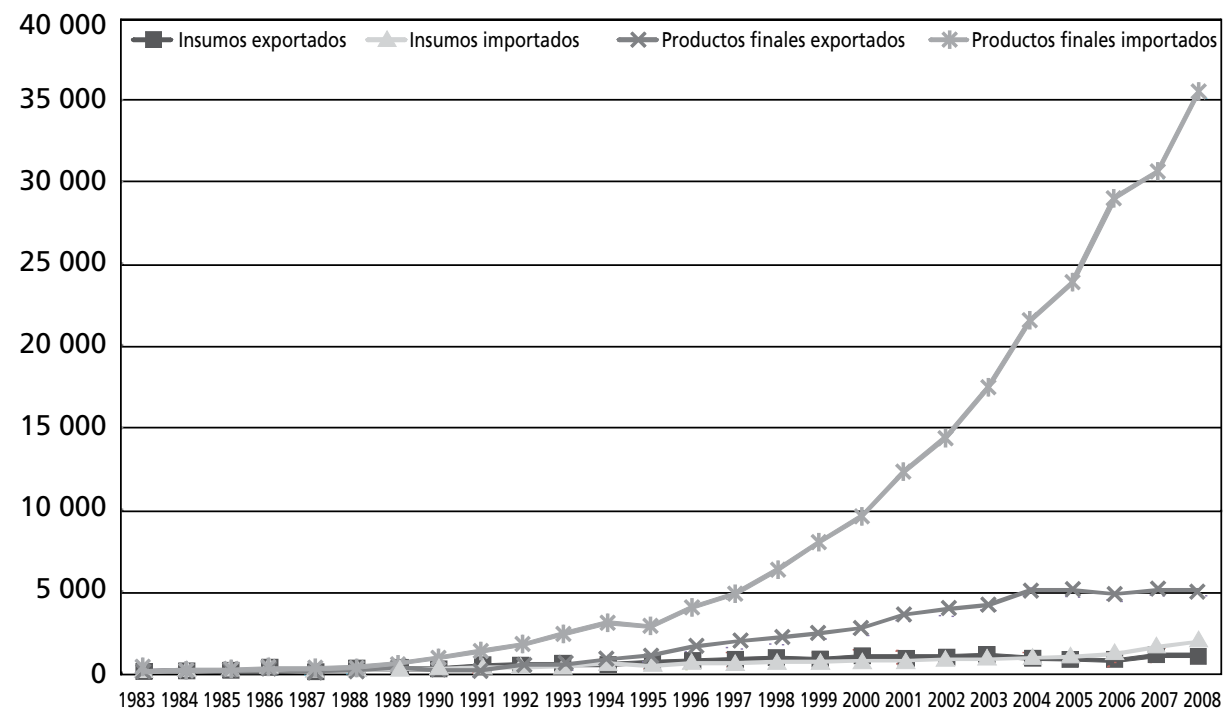

Fuente: Elaboración propia a partir de CEPAL/Badecel (2010).

Cuadro 2. México: exportaciones e importaciones de insumos farmacéuticos y productos finales farmacéuticos de y hacia el mundo

(Miles de dólares)

\begin{tabular}{|c|c|c|c|c|}
\hline & \multicolumn{2}{|c|}{ Insumos } & \multicolumn{2}{c|}{ Productos finales } \\
\hline Periodo & $X$ & $M$ & $X$ & $M$ \\
\hline $1983-1998$ & 1173656 & 3488882 & 1846439 & 1988503 \\
\hline $1999-2008$ & 2349233 & 8523233 & 10674137 & 18160970 \\
\hline Total & $\mathbf{3 5 2 2 8 8 9}$ & $\mathbf{1 2 0 1 2 1 1 5}$ & $\mathbf{1 2 5 2 0 5 7 6}$ & $\mathbf{2 0 1 4 9 4 7 3}$ \\
\hline
\end{tabular}

\begin{tabular}{|c|c|c|c|c|}
\hline $\begin{array}{c}\text { Tasa de } \\
\text { crecimiento }\end{array}$ & \multicolumn{2}{|c|}{ Insumos } & \multicolumn{2}{c|}{ Productos finales } \\
\hline Periodo & $X$ & $M$ & $X$ & $M$ \\
\hline $1989-1998$ & 33.3 & 29.0 & 14.7 & 9.9 \\
\hline $1999-2008$ & 66.7 & 71.0 & 85.3 & 90.1 \\
\hline Total & 100 & 100 & 100 & 100 \\
\hline
\end{tabular}

Fuente: Elaboración propia a partir de CEPAL/Badecel (2010).

$X=$ exportaciones; $M=$ importaciones 


\section{COMERCIO INTRAINDUSTRIAL DE MÉXICO CON EL EXTERIOR}

En general, el comercio intraindustrial (CII) de México con el exterior, o comercio de ida y vuelta, aumentó entre 1983 y 2008 en el rubro de productos finales: en promedio simple para éstos, el índice de Grubel y Lloyd pasó de 0.432 a 0.542 (cuadro 4), lo que se explica seguramente por el aumento del comercio intraempresa (filial-matriz). ${ }^{7}$ Este tipo de comercio es horizontalmente diferenciado, pues se lleva a cabo en virtud de la competencia por precio entre empresas -filiales o no- de diferentes países; es decir, compiten productos de calidad similar en uno y otro país y no se observa integración en los procesos productivos de éstos en dicha industria. ${ }^{8}$ Por lo contrario, y con el fin de establecer una referencia, en la industria maquiladora de exportación el CII del país es muy alto, máxime si se considera únicamente la relación México-Estados Unidos (Gutiérrez, 2007) (véase cuadro 3).

En cuanto al CII de insumos, de 1983 a 2008 éste creció de manera marginal: en promedio simple pasó de 0.158 a 0.186 . Ello evidencia la poca vinculación de los productos nacionales con los extranjeros para fines de producción de bienes de consumo final. Es decir, se observa que las empresas transnacionales de la industria farmacéutica recurren en menor medida a los insumos provenientes de México que a los que producen en su propio país o en sus filiales en otras naciones (véase cuadro 4).

Conviene ahora analizar la composición de las exportaciones e importaciones de insumos y productos finales a partir del CII promedio ponderado (CII- PP) de la industria farmacéutica. Para el caso de los insumos, su comportamiento entre 1983 y 2008 es decreciente, sobre todo entre 1990 y 2003. Para el caso de los productos finales, desde el inicio es alto y con el tiempo crece más (véase cuadro 5).

De lo anterior se infiere que, desde la implantación de los pre ADPIC el CIIPP tendió a bajar en el comercio de insumos y le tomó mucho tiempo regresar al nivel que había alcanzado a fines de los años ochenta. Dicho CIIPP nunca ha superado $65 \%$ del comercio total (éste es igual a la suma de CII y comercio tradicional, tipo Heckscher-Ohlin o de ventajas comparativas) (Gutiérrez, 2007).

\footnotetext{
${ }^{7}$ Esta deducción surge lo mismo de la alta vinculación que encuentra la OCDE (2002) entre el CII y el comercio intraempresa, que del análisis de estudiosos como Gosen y Jasso (2000), que observan que gran parte de las exportaciones de la industria farmacéutica las realizan empresas extranjeras que han seleccionado a México como su plataforma de comercialización (no de producción).

${ }^{8}$ La separación entre CII de insumos farmacéuticos y de productos finales es posible gracias a la apertura estadística de la base de datos CEPAL/Badecel (2010) presentada a través de la nomenclatura de la Clasificación Uniforme para el Comercio Internacional, Revisión 2 (CUCI 2). Ésta se puede consultar lo mismo directamente en CEPAL/Badecel (2010) que en la fuente original, Naciones Unidas (2008).
} 
102 ECONOMÍA: TEORÍA Y PRÁCTICA • Nueva Época, número 35, julio-diciembre 2011

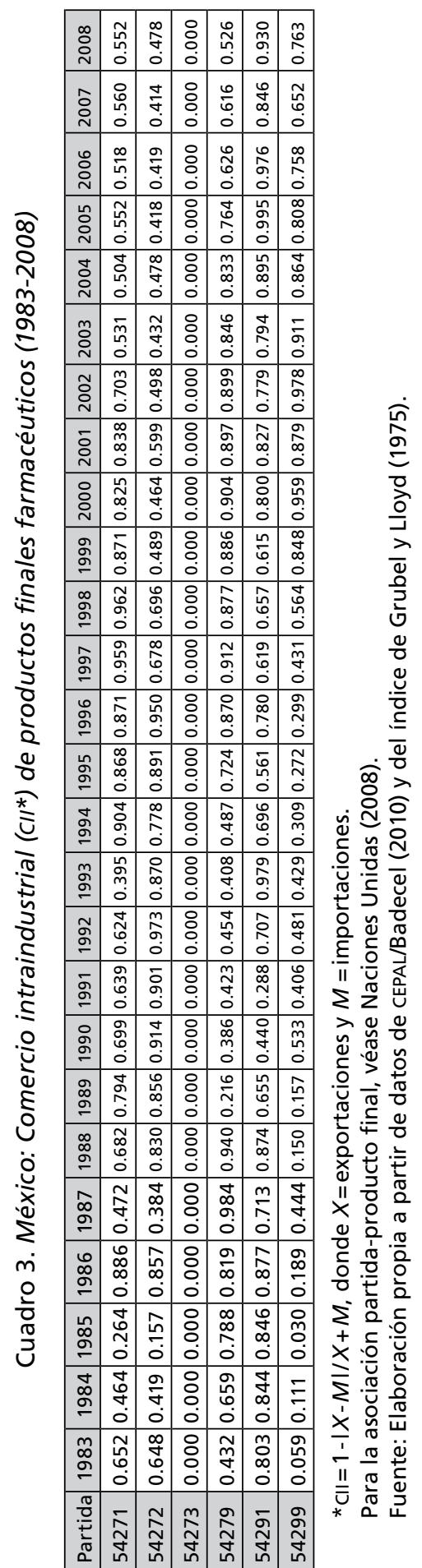

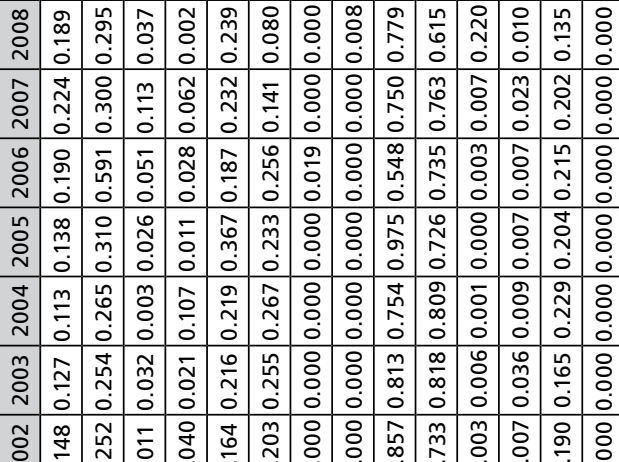

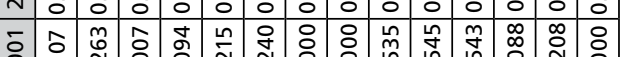

○े

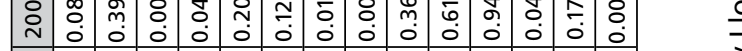

รั

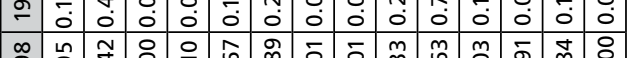

市

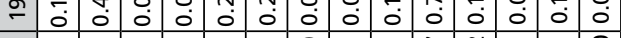

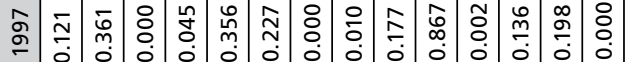

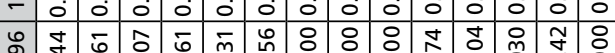

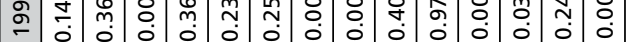

นn

જે

รั

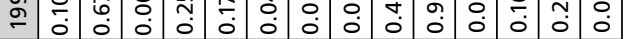

m

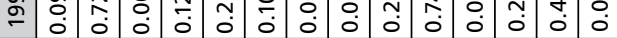

๙ু

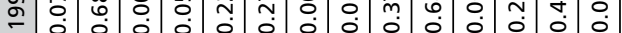

б.

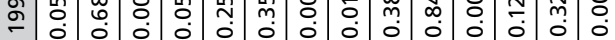

ภํ

-

ळ

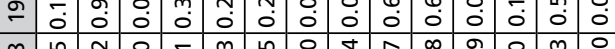

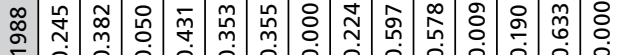

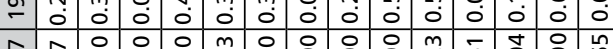

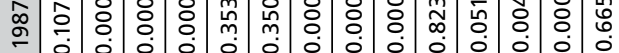

œ

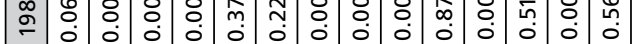

œ

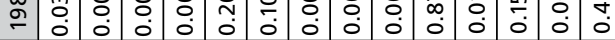

ఫ

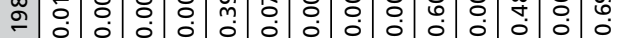

m

๑

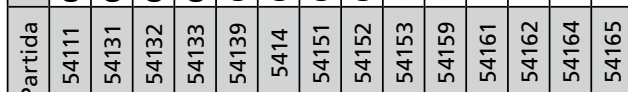

ํํㅇ

응ㅎㅇ

T⿱宀⿻三丨口

过

을 웡 을 25 原 $\lambda \tilde{U}$ ๕ 응 은 은 T)

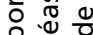
$x>=$ II $x \xi \frac{\pi}{\square}$ $\stackrel{0}{\simeq} \sigma$ 등 ㅎำ 응 응 s $+0$. $\times$ 듬 这造 $\times$ 늠 II 즈 은 흥 
Cuadro 5. Comercio intraindustrial promedio ponderado (CIIPP)* de insumos y productos finales de la industria farmacéutica mexicana (1983-2008)

(Porcentaje)

\begin{tabular}{|c|c|c|}
\hline Años & Insumos & Productos finales \\
\hline 1983 & 30.86 & 78.37 \\
\hline 1984 & 45.03 & 75.45 \\
\hline 1985 & 42.48 & 67.34 \\
\hline 1986 & 53.93 & 65.14 \\
\hline 1987 & 51.66 & 89.88 \\
\hline 1988 & 64.06 & 85.36 \\
\hline 1989 & 52.85 & 29.69 \\
\hline 1990 & 52.53 & 73.60 \\
\hline 1991 & 45.65 & 79.93 \\
\hline 1992 & 43.68 & 58.51 \\
\hline 1993 & 45.06 & 60.16 \\
\hline 1994 & 42.01 & 62.75 \\
\hline 1995 & 42.14 & 65.69 \\
\hline 1996 & 40.70 & 73.90 \\
\hline 1997 & 38.66 & 79.25 \\
\hline 1998 & 36.86 & 83.25 \\
\hline 1999 & 33.64 & 87.80 \\
\hline 2000 & 33.39 & 91.02 \\
\hline 2001 & 36.33 & 92.90 \\
\hline 2002 & 38.27 & 89.41 \\
\hline 2003 & 35.06 & 87.55 \\
\hline 2004 & 44.03 & 90.07 \\
\hline 2005 & 55.08 & 92.38 \\
\hline 2006 & 62.13 & 93.66 \\
\hline 2007 & 57.03 & 92.14 \\
\hline 2008 & 54.28 & 89.54 \\
\hline
\end{tabular}

Fuente: Elaboración propia a partir de datos de CEPAL/Badecel (2010).

*En este caso la fórmula pertinente es: IGLPPjk $=1-\frac{1}{2} \Sigma\left|\frac{X_{j k i}}{\Sigma X_{j k i}}-\left(\frac{M_{j k i}}{\Sigma M_{j k i}}\right)\right|$, citada por Gutiérrez (2007), donde $X=$ exportaciones, $M=$ importaciones, $j=$ país de origen, $k=$ país de destino, $i=$ año o periodo. (Esta fórmula fue desarrollada originalmente por Michaely, 1972, y adaptada al CII por Grubel y LLoyd, 1975.)

En cambio, en el caso del CIIPP de productos finales, desde 1990 ha sido superior a 70\% del comercio total, y para 2008 se acercó a $90 \%$, lo que significa que México vende y compra a otros países productos de consumo final ligeramente diferenciados, lo cual corresponde al CII horizontalmente diferenciado 
previsto por Linder (1961). Tal tipo de comercio deja fuera posibles diferenciales en materia de habilidades productivas nacionales, vía integración de cadenas productivas globales, o evidencias de competitividad tecnológica por parte de la industria mexicana. Existen razones para suponer que se trata de un tipo de comercio que así conviene a las empresas transnacionales.

Con la idea de reforzar las afirmaciones anteriores, en el cuadro 6 se presenta un ejercicio de correlación entre el comercio intraindustrial promedio ponderado (CIIPP) y el saldo comercial promedio, en valores absolutos (saldo $|X-M|$ ), para el periodo $1983-2008 .^{9}$

Cuadro 6. Coeficiente de correlación de insumos y productos finales de la industria farmacéutica mexicana respecto a IX-MI (1983-2008)

\begin{tabular}{|c|c|c|c|c|}
\hline \multirow{2}{*}{ Año } & \multicolumn{2}{|c|}{ Insumos } & \multicolumn{2}{|c|}{ Productos finales } \\
\hline & CIIPP* & $|X-M|^{* *}$ & CIIPP* & $|X-M|^{* *}$ \\
\hline 1983 & 30.86 & 55392 & 78.37 & 15568 \\
\hline 1984 & 45.03 & 68263 & 75.45 & 7341 \\
\hline 1985 & 42.48 & 88078 & 67.34 & 499 \\
\hline 1986 & 53.93 & 76133 & 65.14 & 28114 \\
\hline 1987 & 51.66 & 88933 & 89.88 & 1125 \\
\hline 1988 & 64.06 & 93905 & 85.36 & 900 \\
\hline 1989 & 52.85 & 115390 & 29.69 & 25925 \\
\hline 1990 & 52.53 & 135092 & 73.60 & -46318 \\
\hline 1991 & 45.65 & 150046 & 79.93 & -75361 \\
\hline 1992 & 43.68 & 168454 & 58.51 & -34052 \\
\hline 1993 & 45.06 & 212642 & 60.16 & -85568 \\
\hline 1994 & 42.01 & 306375 & 62.75 & -71636 \\
\hline 1995 & 42.14 & 204354 & 65.69 & 16840 \\
\hline 1996 & 40.70 & 288243 & 73.90 & 39627 \\
\hline 1997 & 38.66 & 263926 & 79.25 & 34932 \\
\hline 1998 & 36.86 & 334205 & 83.25 & -33074 \\
\hline 1999 & 33.64 & 344327 & 87.80 & -108437 \\
\hline
\end{tabular}

${ }^{9}$ El coeficiente de correlación $(r)$ provee una medida de la manera en que dos variables aleatorias están asociadas en una "muestra" y constituye una medida de la intensidad de la relación lineal de dichas variables. Las tres propiedades matemáticas de $r$ son: 1) los valores de $r$ se ubican en un rango de entre -1 y 1.2) $r$ es independiente de las unidades de medida de las variables $X$ y $Y$. 3) del punto 1 se deduce que $r$ puede tener un valor positivo, negativo o cero. 
Cuadro 6. Coeficiente de correlación de insumos y productos finales de la industria farmacéutica mexicana respecto a IX-MI (1983-2008)

(Conclusión)

\begin{tabular}{|c|c|c|c|c|}
\hline \multirow{2}{*}{ Año } & \multicolumn{2}{|c|}{ Insumos } & \multicolumn{2}{|c|}{ Productos finales } \\
\hline & CIIPP* & $|X-M| * *$ & CIIPP* & $|X-M|^{* *}$ \\
\hline 2000 & 33.39 & 356300 & 91.02 & -173170 \\
\hline 2001 & 36.33 & 325472 & 92.90 & -206663 \\
\hline 2002 & 38.27 & 382829 & 89.41 & -305902 \\
\hline 2003 & 35.06 & 414376 & 87.55 & -504557 \\
\hline 2004 & 44.03 & 474164 & 90.07 & -647300 \\
\hline 2005 & 55.08 & 566291 & 92.38 & -859318 \\
\hline 2006 & 62.13 & 742875 & 93.66 & -1361478 \\
\hline 2007 & 57.03 & 955495 & 92.14 & -1430437 \\
\hline 2008 & 54.28 & 1277666 & 89.54 & -1856497 \\
\hline $\begin{array}{l}\text { Coeficiente de } \\
\text { correlación }\end{array}$ & & 0.2742 & & -0.4744 \\
\hline
\end{tabular}

Fuente: Elaboración propia a partir de datos de Badecel.

* Porcentaje.

** Valor absoluto (los negativos se dejan sólo por razones indicativas ya que, en estricto sentido, el encabezado indica que se hace abstracción del signo).

Los resultados demuestran que, al menos para el caso de productos finales, existe una enorme vinculación entre el desarrollo de la variable CIIPP y el déficit comercial en términos absolutos. Esto quiere decir que, aunque el CIIPP es deseable para una economía porque denota ventajas comparativas adquiridas - es decir, aprendizaje - a medida que aumenta provoca que se ahonde el diferencial entre exportaciones e importaciones y, atendiendo al valor del signo, hace que la balanza comercial sea más deficitaria. No sucede lo mismo con el comercio de insumos, donde la correlación es muy baja, lo que quiere decir que el país puede aumentar su CIIPP de estos productos sin temor alguno de afectar su saldo comercial.

\section{LOS ADPIC Y LA INNOVACIÓN TECNOLÓGICA EN LOS PVD}

Es importante resaltar la coincidencia de un amplio grupo de expertos de la industria farmacéutica en torno al hecho de que, al encontrarse ésta dominada por empresas transnacionales y al tener que sujetarse los países en vía de desarrollo (PVD) a los DPI establecidos por la OMC, la aplicación de los pre ADPIC en países 
como México, a principios de la década de los noventa, y de los ADPIC en el ámbito internacional unos años después, no sólo provocó una mayor concentración de la actividad inventiva y de innovación tecnológica en los países desarrollados, sino que ha acentuado el interés de las empresas farmacéuticas internacionales por la innovación de medicamentos que les generan mayores utilidades y no por los que corresponderían a las necesidades de salud de la población de los PVD. Más aún, han acotado al máximo la capacidad que tenían los PVD de producir medicamentos genéricos, lo mismo de primera necesidad que acordes con su transición epidemiológica. He aquí algunas opiniones al respecto. Ortún (2004) afirma:

... Los defensores de los DPI creen que lo que ha funcionado para los países ricos también ha de funcionar para los pobres: estímulo a la innovación y a la producción, atracción de inversiones y transferencia de tecnología, disponibilidad de medicamentos más eficaces. En ausencia, no obstante, de capacidad humana y técnica para innovar, los DPI impedirán el aprendizaje por imitación, fomentarán la sustitución de la industria doméstica a través de importaciones protegidas por patentes y aumentarán los costes de los medicamentos (y otros insumos).

Las industrias farmacéuticas locales de los países en desarrollo orientan en general sus estrategias de desarrollo hacia la imitación, pero a partir de la producción de medicamentos genéricos. Sólo algunos países (como Corea e India) transitan paulatinamente de la imitación hacia la innovación, y en otros esto se hace de manera muy marginal, como en México, Brasil y Argentina (Guzmán y Viniegra 2005b).

La estrategia imitativa era de uso recurrente para las empresas farmacéuticas mexicanas en la producción de medicamentos antes de los cambios legislativos de principios de los noventa.

... La vía imitativa posibilita que los países más atrasados potencien su desarrollo; pero que alguno de ellos alcance o incluso supere los niveles de los países líderes implica que los primeros han transitado hacia la actividad innovativa endógena. [Es en este sentido innegable que, de permitirse] la estrategia imitativa, posibilitará a los países con rezago tecnológico respecto a la frontera mundial de innovación aumentar su tasa de crecimiento económico (Guzmán et al., 2004). 
Una de las peculiaridades del caso mexicano y de “... los países latinoamericanos es que han optado por un modelo de desarrollo basado en la promoción de exportaciones y la atracción de IED, lo que en principio ha relegado el desarrollo endógeno local a un segundo plano" (Martínez, 2008b). Por si fuera poco, la instauración de los DPI a nivel internacional da como resultado inmediato para los países en desarrollo en los cuales existían patentes que "los productores locales no las pueden copiar ni se pueden importar de proveedores de genéricos de otros países" (Intermón Oxfam, 2001). Por tanto, no hay forma de garantizar la producción de medicamentos que cubran las necesidades básicas de salud.

Debido al conflicto inherente entre los intereses público y privado, las leyes de patentes que protegen con firmeza a éste son débiles para proteger a aquél (Shiva, 2003, p. 11). Por ello las patentes son intrínsecamente una fuente de confrontación: encarnan los conflictos entre los derechos individuales y el interés público. Los sistemas de patentes constituyen el terreno de discusión de un conflicto básico entre la propiedad privada, la creación de monopolios y los beneficios privados, frente al interés público y los beneficios sociales de la ciencia y la tecnología (Shiva, 2003, p. 11).

Un argumento económico a favor de la protección a la propiedad intelectual se basa en la existencia de una falla de mercado: al no reconocerse por sí solo la propiedad de lo inventado, se hace necesaria y justificable la actuación del Estado para corregir la falla, otorgando un derecho exclusivo, en este caso una patente, al autor de la invención. La no intervención del Estado en la corrección de esta falla genera la idea de que: “... la creación de conocimientos, como la de otros bienes públicos, al no depender del nivel de consumo, no tiene rival ni es de carácter excluyente (por lo que es fácil de reproducir) y su costo original de producción es alto" (PNUD, 2003, p. 201). Con la protección se limita o restringe el acceso al invento y se generaliza la idea de que con el simple hecho de hacer escaso el producto, dándole valor de mercado por parte del gobierno a partir del otorgamiento de una figura jurídica (de las que se vale la protección a la propiedad intelectual) se le está otorgando a un inventor un monopolio sobre la explotación de lo protegido.

El artículo 1711 del TLCAN de 1992 establece una norma sobre exclusividad que exige a todos los países signatarios un periodo mínimo de exclusividad de cinco años a partir de la fecha de aprobación de la comercialización del producto (Correa, 2002), lo cual favorece indudablemente a la industria farmacéutica estadounidense. Es el TLCAN, en ese sentido, el primer acuerdo entre países asimétricos previo a la aplicación generalizada de los ADPIC que incluye 
disposiciones estrictas en materia de DPI (Roffe, 2008). Así, el TLCAN impulsó la posición de Estados Unidos como primer exportador de productos farmacéuticos a México, superando a Francia y Suiza, que en el pasado eran los dos principales (Krazov-Jinich, 2003).

Cabe recordar que Estados Unidos fue el promotor del primer tratado multilateral de propiedad intelectual (Convenio de París de 1883) y desempeñó un papel preponderante para incluir el tema en la Ronda de Uruguay, que culminó con la creación de los ADPIC. Asimismo, el TLCAN fue el primer acuerdo comercial previo a los ADPIC con disposiciones estrictas en la materia, y que abrió brecha para el contenido de diversos acuerdos bilaterales" (Martínez, 2008 a).

Si se observa que “... de los 1219 nuevos medicamentos que entraron al mercado mundial entre 1975 y mediados de 1998, sólo 11 se enfocaron a enfermedades tropicales como la malaria, a enfermedades diarreicas o a parasitosis, esto implica que no se está realizando innovación farmacéutica en los países en vías de desarrollo..." (Trens, 2000). De 1998 hasta la fecha la investigación orientada a enfermedades "tropicales" de los países en desarrollo no ha cambiado; más bien se asiste a una profundización en el desinterés por parte de los grandes laboratorios internacionales. ${ }^{10}$

Es en este sentido que se considera que las patentes farmacéuticas retrasan la comercialización de nuevos medicamentos en los PVD durante los primeros años de vida de una nueva terapia, cuestión de especial relevancia para evaluar el efecto de los acuerdos internacionales acerca de la propiedad intelectual sobre la disponibilidad de fármacos capaces de frenar el rápido avance en estos países de enfermedades contagiosas como el VIH/sida. (Borrel, 2004).

Es decir, “... las patentes aceleran la comercialización de los nuevos medicamentos en los países en desarrollo tan sólo cuando ya han pasado algunos años (entre uno y cuatro) desde su primera comercialización en Estados Unidos. ... Estos resultados sugieren que las patentes permiten a las multinacionales obtener beneficios mayores en los países con ingresos medio y bajo; con ello, incentivan la introducción de nuevos medicamentos" (Borrel, 2004).

En el contexto de los DPI para los países en desarrollo y el acceso de éstos a los medicamentos, “... las patentes se utilizan como instrumento para im-

\footnotetext{
${ }^{10}$ Las farmacéuticas transnacionales destinan $85 \%$ de su gasto en investigación y desarrollo a las enfermedades características de los países ricos (cáncer, hipertensión arterial, diabetes, reumatismo, etcétera) y sólo 5\% a los problemas de salud de los países de bajos ingresos (infecciones tropicales, tuberculosis, etcétera) (Guzmán y Viniegra, 2005 b).
} 
pedir la transferencia de tecnología de los países avanzados, y la transferencia de conocimiento se considera 'piratería'" (Shiva, 2003 y p. 20).

\section{EFECTO DE LOS ADPIC EN LA CONCENTRACIÓN INVENTIVA DE LA INDUSTRIA FARMACÉUTICA DE MÉXICO ${ }^{11}$}

La producción de conocimiento patentado de la industria farmacéutica en México se puede categorizar por fases. La primera, que se extiende de 1980 (o antes, si se toma en cuenta el modelo ISI) hasta 1990, resaltaría el uso de la estrategia imitativa, en la que las empresas se beneficiaban al no tener que esperar la expiración de la patente del producto original para traer su producto al mercado (Moïse y Docteur, 2007). La segunda, de 1991 a 1996, sería la fase pre ADPIC, caracterizada por la negociación y puesta en operación de los cambios legislativos que afectarían el proceso tradicional de transferencia e innovación tecnológica de la industria. Y la tercera sería la fase de los ADPIC, en la cual se homogenizan los DPI a nivel internacional. El cuadro 7 presenta la producción de conocimiento patentado en México durante estas tres fases.

\section{Cuadro 7. Patentes de la industria farmacéutica de México otorgadas por fases (1980-2007), CIP: $A 61 K^{*}$}

\begin{tabular}{|l|c|c|c|c|}
\hline \multicolumn{1}{|c|}{ Fase } & Periodo & Solicitadas & Otorgadas & Tcon** $^{*}$ \\
\hline Imitativa & $1980-1990$ & 90 & 89 & 3.54 \\
\hline Pre ADPIC & $1991-1996$ & 5200 & 3022 & 0.93 \\
\hline ADPIC & $1997-2007$ & 26869 & 12933 & 0.85 \\
\hline
\end{tabular}

Fuente: Elaboración propia con datos de SIGA-IMPI (varios años).

La fase imitativa 1980-1990 hace referencia a los certificados de invención (CI).

El año de 1988 incluye en las solicitadas dos patentes y en las otorgadas una; los datos restantes son de los $\mathrm{Cl}$.

* Clasificación Internacional de Patentes en el área médica. Tcon=Tasa de concesión de patentes, es decir, otorgadas/solicitadas. De 2007-2010.

** No incluye toda la información porque no se tuvo acceso a ella. Sin embargo, la tendencia es creciente si se toman totales de la CIP: A61K.

${ }^{11}$ En éste y el siguiente apartado se analizan el efecto de la entrada en vigor de los ADPIC en la producción de conocimiento patentado y la competitividad a través del TradecAN. El CANálisis, cabe aclarar, sólo sirve para medir la competitividad de las naciones, pero no genera información estadística sobre cambio tecnológico, comercio u otras variables; es decir, se trata de un programa, no de una base de datos. Al presentar en este orden los dos apartados queda clara la complementariedad entre uno y otro tópico. 
En las fases pre ADPIC y ADPIC las empresas transnacionales han encontrado un entorno favorable a la protección, y han incrementado su registro de patentes para gozar de una mayor certidumbre en la comercialización o incluso en la elaboración de sus productos en el país. Mientras, las empresas nacionales han encontrado mayores obstáculos para la apropiación de conocimiento que en algunos casos era prácticamente de dominio público y ahora ha sido patentado. La actividad imitativa de las empresas locales no sólo se ve limitada por las reformas de los DPI sino también por la nueva normativa de los genéricos y el registro sanitario vinculado a la patente (Guzmán y Viniegra, 2005 a).

Antes de la publicación de la LPI, en junio de 1991, la industria farmacéutica mexicana protegía su actividad inventiva a partir de los certificados de invención. Esto en virtud de que todo lo referente a la industria farmacéutica no entraba en el campo de la materia patentable. La nueva ley incluyó los productos de esta industria en la esfera patentable. Asimismo, cambió la protección a partir de la fecha de presentación y ya no de la fecha de otorgamiento, como sucedía anteriormente. ${ }^{12}$

A continuación se presentan los resultados de la búsqueda de producción de conocimiento patentado en las principales empresas de la industria farmacéutica en México (OCDE, 2009) agrupadas en la Asociación Mexicana de Industrias de Investigación Farmacéutica (AMIIF) y en la Asociación Nacional de Fabricantes de Medicamentos (ANAFAM). Como se observa en el cuadro 8, fue a partir de 1991, con la puesta en vigor de la LPI, que tanto las solicitudes como el otorgamiento de patentes para la actividad inventiva de la industria farmacéutica empezaron a registrar un aumento acelerado. Aunque la relación entre ambas

${ }^{12}$ El artículo décimo primero transitorio de la LPI dice a la letra: "Las solicitudes en trámite de certificado de invención y las de patente relativas a procesos de los que se obtenga directamente un producto que no fuera patentable conforme a la Ley de Invenciones y Marcas que se abroga, pero sí conforme a esta Ley, podrán convertirse en solicitudes de patente para dicho producto, conservando su fecha de presentación o de prioridad reconocida, sólo que cumplan con lo siguiente: I.Que la conversión sea promovida por escrito ante la Secretaría por el solicitante del certificado de invención o de la patente o por sus causahabientes, dentro de los 12 meses siguientes a la fecha en que entre en vigor esta Ley; II.- Que el solicitante tenga patentado el producto o hubiese presentado una solicitud de patente para el mismo en algún país miembro del Tratado de Cooperación en Materia de Patentes; III.- La publicación de estas solicitudes de patente en la Gaceta se hará en la fecha más próxima posterior a los 18 meses siguientes a aquella en que se promueva la conversión, y IV.- Las patentes que se otorguen en base a lo dispuesto en este precepto tendrán una vigencia de 20 años a partir de la fecha de presentación de la solicitud de certificado de invención o patente de proceso" (DOF, 1991). 
(Tcon $=$ tasa de concesión) es en promedio de $49.9 \%$ para el periodo, se observa claramente un descenso después de la puesta en operación del TLCAN.

Cuadro 8. Producción de patentes para la CIP: A61 $K^{*}$ en México (1980-2010)

\begin{tabular}{|c|c|c|c|}
\hline Año & Solicitadas & Otorgadas & Tcon (\%) \\
\hline 1980 & 23 & nd & nd \\
\hline 1981 & 13 & 1 & 7.7 \\
\hline 1982 & 19 & nd & nd \\
\hline 1983 & 16 & nd & nd \\
\hline 1984 & 5 & 12 & 240 \\
\hline 1985 & 11 & 1 & 9.1 \\
\hline 1986 & 1 & 6 & 600 \\
\hline 1987 & n.d. & 28 & n.d. \\
\hline 1988 & 2 & 14 & 700 \\
\hline 1989 & n.d. & 13 & n.d. \\
\hline 1990 & n.d. & 14 & n.d. \\
\hline 1991 & 303 & 157 & 51.8 \\
\hline 1992 & 1469 & 916 & 62.3 \\
\hline 1993 & 1100 & 523 & 47.5 \\
\hline 1994 & 1234 & 656 & 53.2 \\
\hline 1995 & 403 & 285 & 70.7 \\
\hline 1996 & 691 & 485 & 70.2 \\
\hline 1997 & 1635 & 951 & 58.2 \\
\hline 1998 & 1565 & 943 & 60.3 \\
\hline 1999 & 1963 & 1122 & 57.2 \\
\hline 2000 & 2313 & 1220 & 52.7 \\
\hline 2001 & 2601 & 1354 & 52.1 \\
\hline 2002 & 2582 & 1443 & 55.9 \\
\hline 2003 & 2655 & 1409 & 53.1 \\
\hline 2004 & 3147 & 1658 & 52.7 \\
\hline 2005 & 3334 & 1451 & 43.5 \\
\hline 2006 & 3383 & 1044 & 30.9 \\
\hline 2007 & 1650 & 326 & 19.8 \\
\hline 2008 & 22 & 8 & 36.4 \\
\hline 2009 & 16 & 4 & 25 \\
\hline 2010 & 3 & 0 & n.d. \\
\hline Total & 32159 & 16044 & 49.9 ** \\
\hline
\end{tabular}

Fuente: Elaboración propia a partir de datos de SIGA-IMPI (varios años).

El periodo 1980-1990 hace referencia a los certificados de invención (Cl) y no es posible cuantificar la tasa de concesión. (Tcon: otorgadas/solicitadas). El año de 1988 incluye en las solicitadas dos patentes y en las otorgadas una, los datos restantes son de los CI. De 2007 a 2010 no se incluye toda la información porque no se tuvo acceso. Sin embargo, la tendencia es creciente si se toman totales de la CIP: A61K.

* Clasificación Internacional de Patentes en el área médica.

** Promedio 1991-2006. 
112 ECONOMÍA: TEORÍA Y PRÁCTICA • Nueva Época, número 35, julio-diciembre 2011

Cuadro 9. Producción de conocimiento patentado por nacionalidad de las empresas de la AMIIF en México (1991-2007), CIP: A61K*

\begin{tabular}{|c|c|c|}
\hline Empresas & Solicitadas & Otorgadas \\
\hline Pfizer, s.A. de C.v. (Estados Unidos) & 1233 & 588 \\
\hline Sanofi Aventis de México (Alemania) & 1019 & 710 \\
\hline Grupo Roche Syntex de México, S.A. de C.v. (SUIzA) & 755 & 564 \\
\hline Schering Plough (Estados Unidos) & 722 & 374 \\
\hline Astra Zeneca (Reino Unido) & 709 & 342 \\
\hline Novartis Farmacéutica, S.A. de C.v. (Suiza) & 706 & 384 \\
\hline Merck Sharp \& Dhome de México, S.A. de C.V. (EUA) & 654 & 263 \\
\hline Wyeth (Estados Unidos) & 591 & 295 \\
\hline Abbott Laboratories México (Estados Unidos) & 530 & 255 \\
\hline Boehringer Ingelheim Promeco (Alemania) & 520 & 279 \\
\hline Eli Lilly de México (Estados Unidos) & 496 & 199 \\
\hline Bayer de México (Alemania) & 459 & 231 \\
\hline Bristol Myers Squibb de México (Estados Unidos) & 341 & 171 \\
\hline Glaxo Smith Kline México (Reino Unido) & 320 & 135 \\
\hline Amgen Investigación y Desarrollo (Estados Unidos) & 244 & 121 \\
\hline Janssen-Cilag, S.A. de C.v. (Suiza) & 226 & 164 \\
\hline Novo Nordisk Pharma, S.A. de C.V. (Estados Unidos) & 145 & 38 \\
\hline Grunenthal de México, S.A. de C.v. (Alemania) & 101 & 76 \\
\hline Lundbeck México S.A. de C.V. (Dinamarca) & 98 & 49 \\
\hline Pierre Fabre Medicament (Francia) & 52 & 34 \\
\hline Labotarorios Almirall S.A. de C.V. (España) & 33 & 20 \\
\hline UCB de México (Bélgica) & 30 & 19 \\
\hline Ferring Productos Farmacéuticos (Estados Unidos) & 28 & 21 \\
\hline Merz Pharma, S.A. de C.v. (Alemania) & 25 & 12 \\
\hline Armstrong Laboratorios de México & n.d. & n.d. \\
\hline Genzime Corporation (Reino Unido) & n.d. & n.d. \\
\hline Hospira, S. de R.L. de C.V. (Estados Unidos) & n.d. & n.d. \\
\hline Laboratorio Sanfer, S.A. de C.V. (México) & n.d. & n.d. \\
\hline Laboratorios Grossmann, S.A. de C.V. & n.d. & n.d. \\
\hline Labotarorios Carnot (México) & n.d. & n.d. \\
\hline More Pharma Corporation, S. de R.L. de C.V. & n.d. & n.d. \\
\hline Nicomed, S.A. de C.V. (Alemania) & n.d. & n.d. \\
\hline Productos Farmacéuticos, S.A. de C.v. (México) & n.d. & n.d. \\
\hline Total & 10037 & 5344 \\
\hline Promedio & 418 & 223 \\
\hline
\end{tabular}

Fuente: Elaboración propia a partir de datos de IMPI-SIGA, varios años.

* Se refiere a Clasificación Internacional de Patentes en el área médica. 
La reforma de las patentes en este país parece haber favorecido a las empresas transnacionales. El predominio de las patentes de no residentes en la farmacéutica muestra que la actividad inventiva local es marginal y sugiere que hay una desconexión entre las dos fuentes de invención en México (Guzmán y Viniegra, 2005b). El resultado de esto es el incremento en el registro de patentes de dichas empresas, para gozar de una mayor certidumbre en la comercialización, o incluso la producción, de sus productos en el país (véase cuadro 9).

De las 11 principales empresas, medidas por sus solicitudes de patentes, seis corresponden a Estados Unidos, dos a Alemania y Suiza, y una a Reino Unido, resultados que a primera vista determinan cuáles países se ha beneficiado más con los cambios legislativos que derivaron en que los DPI incluyeran a la industria farmacéutica.

La actividad imitativa de las empresas locales no sólo se ve limitada por las reformas de los DPI sino también por la nueva normativa de los genéricos y el registro sanitario vinculado a la patente (Guzmán y Viniegra, 2005b). La adopción de los ADPIC erosionó a las empresas farmacéuticas mexicanas que habían construido sus capacidades productivas por la vía imitativa (copy products), de acuerdo con el concepto de Mansfield (1986). Esto las desplazó del mercado de productos con ingrediente activo y las constriñó al de genéricos intercambiables ${ }^{13}$ (véase cuadro 10 ).

En el pasado, las industrias farmacéutica y farmoquímica no realizaban investigaciones sobre nuevas moléculas; sus esfuerzos los concentraban en el mejoramiento de procesos. Es innegable que la industria nacional en México es dominada por las empresas de genéricos intercambiables, lo que significa que México importa la mayor parte de los productos finales que consume. Esto explica por qué los mayores exportadores al mercado mexicano son países con una importante industria farmacéutica.

Después de la puesta en operación de los pre ADPIC, el número de empresas nacionales que producían ingredientes activos disminuyó, al pasar de 94 en 1987 a 48 en 1994 y a 26 en 2005 (Moïse y Docteur, 2007). Además, se dio un proceso de fusión (Nieto, 2010):

\footnotetext{
${ }^{13}$ Las empresas agrupadas en la AMIIF, que representa a las empresas farmacéuticas extranjeras y tiene una participación de mercado de $86 \%$, producen casi la totalidad de los productos originales fabricados en el país (Moïse y Docteur, 2007). Por otra parte, alrededor de $70 \%$ del pago global de derechos de patente y cuotas de licencia se compone de transacciones entre la empresa matriz y sus filiales (Shiva, 2003, p. 11).
} 
114 ECONOMÍA: TEORÍA Y PRÁCTICA • Nueva Época, número 35, julio-diciembre 2011

Cuadro 10. Producción de conocimiento de las empresas de la ANAFAM en el mercado mexicano (1991-2007), CIP: A61K*

\begin{tabular}{|l|c|c|}
\hline \multicolumn{1}{|c|}{ Empresas } & Solicitadas & Otorgadas \\
\hline Sandoz, S.A. de C.V. (Suiza) & 34 & 1 \\
\hline Laboratorios Silanes, S.A. de C.v. (México) & 5 & 1 \\
\hline Apotex, S.A. de C.v. (Canadá) & 3 & 0 \\
\hline Laboratorios Liomont, S.A. de C.v. (México) & 1 & 1 \\
\hline Laboratorios Pisa, S.A. de C.v. (México) & 1 & 1 \\
\hline Laboratorios Psicofarma, S.A. de C.v. (México) & 1 & 1 \\
\hline Industrias Suanca, S.A. de C.v. (México) & n.d. & n.d. \\
\hline Investigación Farmacéutica, S.A. de C.v. (México) & n.d. & n.d. \\
\hline Laboratorios Alpharma, S.A. de C.v. (México) & n.d. & n.d. \\
\hline Laboratorios Hormona, S.A. de C.v. (México) & n.d. & n.d. \\
\hline Laboratorios Kener, S.A. (México) & n.d. & n.d. \\
\hline Laboratorios Keton, S.A. de C.v. (México) & n.d. & n.d. \\
\hline Laboratorios Manuell, S.A. de C.v. (México) & n.d. & n.d. \\
\hline Laboratorios Pharmaservice, S.A. de C.v. (México) & n.d. & n.d. \\
\hline Laboratorios Probiomed, S.A. de C.v. (México) & n.d. & n.d. \\
\hline Laboratorios Senosiain, S.A. de C.v. (México) & n.d. & n.d. \\
\hline Laboratorios Valdecasas, S.A. de C.v. (México) & n.d. & n.d. \\
\hline Química y Farmacia S.A. de C.v. (Estados Unidos) & n.d. & n.d. \\
\hline Representaciones e Investigaciones Médicas (México) & n.d. & n.d. \\
\hline Sigfried Rhein, S.A. de C.v. (México) & n.d. & n.d. \\
\hline Streger, S.A. de C.v. (México) & n.d. & n.d. \\
\hline Total & $\mathbf{4 5}$ & $\mathbf{5}$ \\
\hline Promedio & $\mathbf{8}$ & $\mathbf{1}$ \\
\hline
\end{tabular}

Fuente: Elaboración propia con datos de IMPI-SIGA (varios años).

* Se refiere a Clasificación Internacional de Patentes en el área médica.

... la integración de laboratorios mexicanos al capital de los grandes laboratorios internacionales se viene registrando con más fuerza desde hace ocho años, tiempo durante el cual hemos visto fusiones, como la de la empresa Protein, la cual fue comprada por los laboratorios canadienses Apotex. O bien la mexicana Lemery, que fue adquirida por la farmacéutica israelí Teva, que a su vez adquirió Ivax Pharmaceuticals.

Guzmán (2005a) considera que la investigación que hacen las farmacéuticas es más bien clínica y nada tiene que ver con el desarrollo de nuevas tecnologías o nuevas moléculas. Más aún, Nieto (2010) explica que: "las transnacionales invierten hasta el $20 \%$ de sus ventas en investigación y desarrollo, pero en sus 
países de origen; aquí sólo invierten en adecuación del producto al mercado, así como en su imagen".

\section{ANÁLISIS DE COMPETITIVIDAD}

El TradecAN es una herramienta de análisis del comercio internacional y de la competitividad de las exportaciones que incluye, en su versión de 2009, a más de 200 países y cerca de 800 productos para un periodo que se extiende de 1984 a 2007. A partir del análisis CAN es posible clasificar el comercio de los países en función de su mayor o menor presencia en los mercados de destino a nivel internacional.

La fuente de información del TradecAN es la base comTrade de la Organización de las Naciones Unidas (ONU) sobre comercio, con la apertura de datos de la Clasificación Uniforme del Comercio Internacional, segunda revisión (CUCI 2). Los países informantes son 73 en total, 23 industrializados y 50 en desarrollo. Dicha información cubre más de $90 \%$ de las importaciones mundiales. Los datos originales de COMTrade son procesados antes de ingresar a las bases de datos del TradeCAN e incluyen: a) las importaciones del mundo industrializado y del mundo en desarrollo desagregada en varios subgrupos de países, y b) el cálculo de promedios móviles de tres años de dichas importaciones. Así por ejemplo, el dato puntual para 1990 se refiere en realidad a las importaciones promedio de los años 1989-1991.

Como herramienta de análisis, el TradecAN tiene algunas limitaciones y muchas ventajas. Dentro de las primeras destacan el no explicar las causas o determinantes de la competitividad, los cambios en la productividad, los cambios tecnológicos, los aspectos institucionales, y no distinguir entre factores endógenos y espurios. Dentro de los segundos destacan la información y las herramientas que proporciona para analizar cuatro aspectos fundamentales de la competitividad, que son:

- Las cuotas de mercado ( $\mathrm{Cm}$ ), que miden el valor de las exportaciones de la industria farmacéutica desde el área de análisis hacia el mundo, presentando al mercado importador como porcentaje del valor total de las importaciones de la industria farmacéutica en el mercado mundial. ${ }^{14}$

\footnotetext{
${ }^{14}$ El área de análisis del presente trabajo es el TLCAN; ésta puede cambiar dependiendo de las necesidades del investigador.
} 
- El porcentaje de exportaciones (Pe), que se refiere al valor de las exportaciones de la industria farmacéutica desde el área de análisis hacia el mundo - región importadora - presentadas como porcentaje del total de exportaciones del área comercial al mercado mundial.

- La especialización (SP), la cual se determina comparando la cuota de mercado del área de análisis para la industria farmacéutica con la cuota de mercado total del área comercial. Si la participación de mercado de la industria farmacéutica es mayor a la participación de mercado total, se dice que el área bajo análisis está especializada en la industria farmacéutica. En caso contrario, la respuesta es que no está especializada.

- Porcentaje de importaciones (Pi); se refiere al valor de las importaciones de la industria farmacéutica en el mercado de la región bajo análisis, expresado como porcentaje del valor total de las importaciones del mercado mundial. La interpretación de esta variable se entiende mejor a partir del esquema 1, y sirve para dar una idea de cómo trabaja el TradecAN. En el análisis, los rubros con un cambio positivo a lo largo del tiempo reciben el calificativo de dinámicos y a los que operan en sentido inverso se les cataloga como estancados.

Esquema 1. Matriz de competitividad

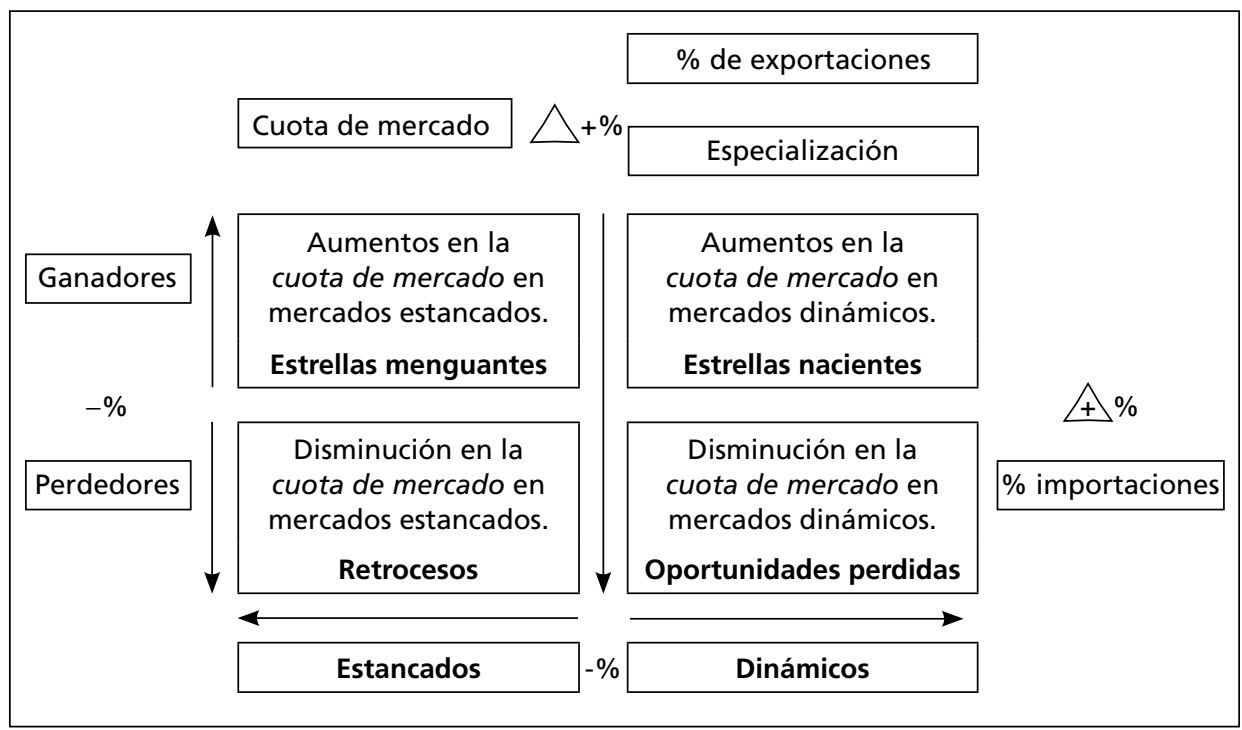

Fuente: Elaboración propia a partir de información del TradecAN (2009). 


\section{El análisis TradeCAN de la industria farmacéutica}

\section{a) Periodización}

1985-1991. En este lapso la industria farmacéutica global no estaba incluida en la agenda comercial relacionada con los DPI, aunque la Ronda Uruguay del GATT consideraba su eventual incorporación a las mesas de negociacion. Esta condición la aprovechaba México para imponer a la industria un esquema de imitación congruente con el modelo ISI, a pesar de que en general ya había iniciado un proceso de liberalización arancelaria desde 1985, previo a su ingreso al GATT. La decisión era justificada porque obedecía a un resquicio de la política industrial que, con la firma del TLCAN, se desvaneció completamente en éste y en otros sectores de la economía. Sin embargo, como nos recuerdan Moïse y Docteur (2007):

En 1987 México reformó el único ordenamiento jurídico que se aplica a las patentes y marcas, y añadió una nueva Ley de Invenciones y Marcas. Este fortalecimiento de su régimen de derechos de propiedad intelectual no fue suficiente para que sus futuros socios comerciales en el TLCAN, Canadá y Estados Unidos, dejaran de insistir en que el país debía fortalecer su derecho de propiedad intelectual. Por tanto, antes de ratificar el TLCAN, el 27 de junio de 1991, México promulgó su Ley de Fomento y Protección de la Propiedad Industrial.

1992-1995. Periodo marcado por cambios legislativos en materia de DPI, impuestos en las negociaciones del TLCAN por Estados Unidos como condición para la firma del tratado, y aplicación de los pre ADPIC.

1996-2007. Aplicación en pleno de los ADPIC en el marco del TLCAN.

\section{b) Análisis regional}

La matriz de competitividad de la industria farmacéutica en el área del TLCAN, presentada en el cuadro 8, muestra que entre 1985 y 2007 la cuota de mercado transitó del rubro de oportunidades perdidas, durante 1985-1991, al de estrella naciente, a partir de 1992, precisamente cuando se adoptaron los pre ADPIC, y posteriormente los ADPIC; el porcentaje de exportación se mantuvo durante los tres subperiodos en el rubro de estrella naciente, y se pasó del de oportunidades perdidas, entre 1985 y 1995, al de estrella naciente, a partir de 1996, lo que casi coincide con la plena puesta en operación del TLCAN. 
Cuadro 11. Situación en la matriz de competitividad de la industria farmacéutica del área TLCAN (1985-2007), CIP: A61K*

\begin{tabular}{|c|c|c|c|}
\hline \multirow{2}{*}{ Periodo } & \multicolumn{3}{|c|}{ TLCAN } \\
\cline { 2 - 4 } & Cuota de mercado & Porcentaje de exportación & Especialización \\
\hline $1985-1991$ & OP & EN & OP \\
\hline $1992-1995$ & EN & EN & OP \\
\hline $1996-2007$ & EN & EN & EN \\
\hline
\end{tabular}

Fuente: Elaboración propia a partir de Tradecan (2009).

$\mathrm{OP}=$ oportunidad perdida, $\mathrm{EN}=$ estrella naciente.

* Se refiere a Clasificación Internacional de Patentes en el área médica.

Cuadro 12. Análisis de competitividad de la industria farmacéutica del área TLCAN (1985-2007), CIP: $A 61 K^{*}$

\begin{tabular}{|c|c|c|c|c|c|c|c|c|c|}
\hline \multirow{2}{*}{ Periodo } & \multicolumn{10}{|c|}{ TLCAN } \\
\cline { 2 - 12 } & \multicolumn{4}{|c|}{ Cuota de mercado } & \multicolumn{1}{|c|}{ Porcentaje de exportación } & \multicolumn{3}{c|}{ Especialización } \\
\hline & $A b$ & $A f$ & $V r$ & $A b$ & $A f$ & $V r$ & $A b$ & $A f$ & $V r$ \\
\hline $1985-1991$ & 15.95 & 12.65 & -20.71 & 0.81 & 0.89 & 9.15 & 0.88 & 0.75 & -14.67 \\
\hline $1992-1995$ & 13.09 & 13.68 & 4.47 & 0.96 & 1.04 & 8.32 & 0.75 & 0.73 & -3.37 \\
\hline $1996-2007$ & 14.32 & 14.80 & 3.37 & 1.10 & 2.78 & 153.66 & 0.75 & 1.00 & 33.81 \\
\hline
\end{tabular}

Fuente: Elaboración propia a partir de TradecAN (2009).

$A b=$ año base; $A f=$ año final; $V r=$ variación.

* Se refiere a Clasificación Internacional de Patentes en el área médica.

En cuanto a la cuota de mercado (primera parte del cuadro 13) los resultados sugieren la consolidación de la industria farmacéutica con la firma del TLCAN, al transitar del rubro de oportunidad perdida, entre 1985-1991, al de estrella naciente, a partir de 1992. Esto bajo la influencia, como se comprobará más adelante, de la dinámica de las industrias estadounidense y canadiense. Empero, debe reconocerse que dicha cuota experimentó en el periodo un pequeño retroceso, al bajar de 15.95 en 1985 a 14.80 en 2007.

Respecto al porcentaje de exportaciones (segunda parte del cuadro 13), dicha variable exhibe permanentemente, a lo largo del periodo de análisis, variaciones positivas, lo que implica estrellas nacientes en los tres subperiodos, con un coeficiente de apropiación del mercado mundial de exportaciones que crece más del triple de punta a punta, ya que pasó de 0.81 en 1985 a 2.78 en 2007.

Finalmente, en lo que respecta a la especialización, los dos primeros periodos (1985-1991 y 1992-1995) caen en el rubro de oportunidades perdidas, mientras que para el periodo 1996-2007 la calificación cambia a estrella naciente. 
Esto se debe a la menor participación del área en el mercado mundial de la industria farmacéutica respecto al mercado mundial de todos los productos durante los dos primeros periodos, situación que se revierte una vez que entra en operación el TLCAN. Es decir, a partir de 1996 el área se especializa, por influencia de Estados Unidos y Canadá, como se verá más adelante, en la industria farmacéutica (además de otras que no se analizan en este trabajo).

\section{c) Análisis por país}

La industria farmacéutica de Canadá, de acuerdo con los resultados del análisis de competitividad presentados en el cuadro 13, es la más dinámica a lo largo del periodo completo; ello debido a que en los tres subperiodos y para los tres rubros que analiza la matriz de competitividad (cuota de mercado, porcentaje de exportación y especialización) presenta estrellas nacientes, es decir, su industra farmacéutica crece dentro de un mercado dinámico.

Estados Unidos, al ser el país con mayor porcentaje tanto en términos de su cuota de mercado y de participación en las exportaciones mundiales como de su especialidad, es el que determina en muchos casos la posición de la industria farmacéutica en los países de América del Norte. Por tanto, no es sorprendente que, en el caso de la especialización, presente oportunidades perdidas para los dos primeros subperiodos (1985-1991 y 1992-1995) y se convierta en estrella naciente en el último (1996-2007), como se vio que sucede para la región en su conjunto.

La cuota de mercado, tanto para México como para Estados Unidos, se inicia y termina con una oportunidad perdida (1985-1991 y 1996-2007), mientras que en el periodo intermedio (1992-1995) se ubica como estrella naciente.

Cuadro 13. Situación de la matriz de competitividad de los tres países miembros del TLCAN (1985-2007), CIP: A61 $K^{*}$

\begin{tabular}{|c|c|c|c|c|c|c|c|c|c|}
\hline \multirow{2}{*}{ Periodo } & \multicolumn{3}{|c|}{ Cuota de mercado } & \multicolumn{3}{|c|}{ Porcentaje de exportación } & \multicolumn{3}{|c|}{ Especialización } \\
\cline { 2 - 10 } & MX & CA & EUA & MX & CA & EUA & MX & CA & EUA \\
\hline $1985-1991$ & OP & EN & OP & EN & EN & OP & OP & EN & OP \\
\hline $1992-1995$ & EN & EN & EN & EN & EN & EN & EN & EN & OP \\
\hline $1996-2007$ & OP & EN & OP & EN & EN & EN & OP & EN & EN \\
\hline
\end{tabular}

Fuente: Elaboración propia a partir de TradeCAN (2009).

* Se refiere a Clasificación Internacional de Patentes en el área médica.

$\mathrm{MX}=$ México, $\mathrm{CA}=$ Canadá, $\mathrm{EUA}=$ Estados Unidos, OP $=$ oportunidad perdida, y EN = estrella naciente. 
Al periodizar de manera cuantitativa el análisis (cuadro 14) se observa que, en materia de cuota de mercado, se da un retroceso de ésta tanto para México como para Estados Unidos entre 1985 y 2007. En el caso de México, el coeficiente baja de 0.45 en el primer año a 0.38 en el segundo, y en el de Estados Unidos de 14.8 en el primero a 12.45 en el segundo. Aun así, es el peso de este país en las exportaciones y la producción mundial de la industria farmacéutica lo que le ha permitido determinar los temas básicos de la agenda comercial e introducir al sector en las deliberaciones del GATT. Como contrapartida, Canadá aumentó su participación de mercado de 0.70 en 1985 a 1.97 en 2007. El análisis sugiere que, si bien el TLCAN generó ganadores y perdedores dentro de la región, en conjunto la región perdió un poco de presencia internacional. Además se observa que, aunque en 1996-2007 Estados Unidos mejoró mucho respecto a 19921995, México empeoró, lo que sitúa a este país como el más afectado de la región.

Cuadro 14. Cuota de mercado de la industria farmacéutica en los tres países miembros del TLCAN (1985-2007)

\begin{tabular}{|c|c|c|c|c|c|c|c|c|c|}
\hline \multirow{2}{*}{ Periodo } & \multicolumn{4}{|c|}{ Cuota de mercado } \\
\cline { 2 - 11 } & \multicolumn{3}{|c|}{$\mathrm{MX}$} & \multicolumn{3}{c|}{ CA } & \multicolumn{3}{c|}{ EUA } \\
\hline & $A b$ & $A f$ & $V r$ & $A b$ & $A f$ & $V r$ & $A b$ & $A f$ & $V r$ \\
\hline $1985-1991$ & 0.45 & 0.31 & -31.80 & 0.70 & 0.72 & 2.24 & 14.80 & 11.63 & -21.46 \\
\hline $1992-1995$ & 0.33 & 0.47 & 43.87 & 0.80 & 1.08 & 35.73 & 11.97 & 12.13 & 1.32 \\
\hline $1996-2007$ & 0.53 & 0.38 & -28.05 & 1.14 & 1.97 & 72.92 & 12.65 & 12.45 & -1.57 \\
\hline
\end{tabular}

Fuente: Elaboración propia a partir de Tradecan (2009).

$M X=$ México, $C A=$ Canadá, $E U A=$ Estados Unidos, $A b=$ año base, $A f=$ año final, $V r=$ variación.

En lo que se refiere al coeficiente de exportación, éste pasa para México de 0.46 , en 1985, a 0.45, en 2007, y alcanza el nivel de estrella naciente en los tres periodos. Dicho nivel lo logra también Canadá, con incrementos continuos y, para el lapso 1992-1995, espectaculares. No sucede lo mismo con Estados Unidos en el primer periodo, ya que su coeficiente se contrae; sin embargo, retoma el crecimiento en 1992-1995 y crece $173 \%$ en 1996-2007. Esto quiere decir que, de la mano del TLCAN, las industrias farmacéuticas de Canadá y Estados Unidos se consolidan como grandes exportadoras, además de ser importantes innovadoras (lo cual no refleja el TradeCAN), en tanto México logra seguir colocando productos farmacéuticos en el mercado y aumentar su porcentaje de exportación, aunque con un desarrollo tecnológico regresivo, ya que sólo produce bienes finales y deja de participar en procesos de innovación. 
Cuadro 15. Porcentaje de exportación de la industria farmacéutica en los tres países miembros del TLCAN (1985-2007)

\begin{tabular}{|c|c|c|c|c|c|c|c|c|c|}
\hline \multirow{2}{*}{ Periodo } & \multicolumn{9}{|c|}{ Corcentaje de exportación } \\
\cline { 2 - 11 } & \multicolumn{3}{|c|}{$\mathrm{MX}$} & \multicolumn{3}{c|}{ CA } & \multicolumn{3}{c|}{ EUA } \\
\hline & $A b$ & $A f$ & $V r$ & $A b$ & $A f$ & $V r$ & $A b$ & $A f$ & $V r$ \\
\hline $1985-1991$ & 0.26 & 0.28 & 7.07 & 0.13 & 0.22 & 70.66 & 1.18 & 1.17 & -1.03 \\
\hline $1992-1995$ & 0.31 & 0.38 & 24.29 & 0.26 & 0.36 & 39.31 & 1.26 & 1.36 & 7.80 \\
\hline $1996-2007$ & 0.41 & 0.45 & 9.88 & 0.39 & 1.55 & 293.49 & 1.43 & 3.89 & 173.03 \\
\hline
\end{tabular}

Fuente: Elaboración propia a partir de TradecAn (2009).

$\mathrm{MX}=$ México, $\mathrm{CA}=$ Canadá, $\mathrm{EUA}=$ Estados Unidos, $\mathrm{Ab}=\mathrm{año}$ base, $\mathrm{Af}=\mathrm{año}$ final, $\mathrm{Vr}=$ variación.

Respecto a la evolución de la especialización (cuadro 16), es evidentemente decreciente en México, al pasar de 0.285 en 1985 a 0.160 en 2007. El punto más alto se alcanzó en 1987 (0.31), el cual no se inscribe en el periodo de apertura del sector, sino en aquel en que, al menos en esta industria, el fomento era nodal. Por su parte, a lo largo del periodo la especialización en la industria farmacéutica canadiense evolucionó de manera positiva, al pasar de 0.14 en 1985 a 0.56 en 2007. Y en Estados Unidos pasó de dos lapsos de oportunidades perdidas (1985-1991, en que su coeficiente bajó de 1.28 a 0.99, y 1992-1995, en que lo volvió a hacer de 0.99 a 0.95) a un periodo (1996-2007) en que se ubica como estrella naciente, al elevar su participación de 0.97 a 1.40, cifra incluso superior a la que ostentaba en 1985.

Cuadro 16. Especialización de la industria farmacéutica de los integrantes del TLCAN (1985-2007)

\begin{tabular}{|c|c|c|c|c|c|c|c|c|c|}
\hline \multirow{2}{*}{ Periodo } & \multicolumn{9}{|c|}{ Especialización } \\
\cline { 2 - 11 } & \multicolumn{3}{|c|}{$M x$} & \multicolumn{3}{c|}{ CA } & \multicolumn{3}{c|}{ EUA } \\
\hline & $A b$ & $A f$ & $V r$ & $A b$ & $A f$ & $V r$ & $A b$ & $A f$ & $V r$ \\
\hline $1985-1991$ & 0.29 & 0.24 & -16.30 & 0.14 & 0.19 & 33.42 & 1.28 & 0.99 & -22.63 \\
\hline $1992-1995$ & 0.24 & 0.27 & 10.88 & 0.21 & 0.25 & 24.28 & 0.99 & 0.95 & -3.83 \\
\hline $1996-2007$ & 0.28 & 0.16 & -42.04 & 0.27 & 0.56 & 107.57 & 0.97 & 1.40 & 44.02 \\
\hline
\end{tabular}

Fuente: Elaboración propia a partir de TradeCAN (2009).

$\mathrm{MX}=$ México, $\mathrm{CA}=$ Canadá, EUA = Estados Unidos, $\mathrm{Ab}=$ año base, $\mathrm{Af}=$ año final, $\mathrm{Vr}=$ variación. 


\section{CONCLUSIONES}

La industria farmacéutica mexicana es un claro ejemplo de la desventaja que, a nivel microeconómico, puede provocar la apertura comercial. Es decir, un país puede volverse más competitivo en términos de su balanza comercial (pasar de déficit crónicos a superávit o cuasi superávit) cuando se abre de manera general (ingreso a la $\mathrm{OMC}$ ) o parcial (firma de acuerdos regionales de liberalización) al comercio internacional, sin que por ello algunas de sus empresas, ramas, industrias o regiones dejen de ser ineficientes o, en el peor de los casos, se vuelvan menos competitivas. Ésta es la razón por la que los acuerdos comerciales, desde su concepción teórica, prevén mecanismos de compensación para apoyar a las industrias afectadas por la apertura (Salvatore, 2005). Para ello se crean los bancos de desarrollo regional, como el banco de Desarrollo de América del Norte o su contraparte en la Unión Europea. Empero, mientras en gran medida gracias al financiamiento países como España, Portugal, Grecia e Irlanda aceleraron su desarrollo (aunque también incurrieron en fuertes déficit fiscales), México ha seguido rezagado y sus áreas menos competitivas continúan empeorando.

Por tanto, se recomienda una visión clara de hacia dónde quiere llegar un país antes de embarcarse en un proceso de apertura comercial, lo cual deberá combinarse con una estrategia adecuada de negociación en la que se cuente con liderazgo y por supuesto con buenos negociadores. Aun sin haber cumplido con esto, después de firmados los acuerdos hay cosas que se pueden hacer. Sin necesidad de renunciar a los organismos comerciales multilaterales y regionales, las empresas, industrias, sectores y regiones más afectados pueden poner en operación políticas públicas orientadas al fomento sectorial, como lo siguen haciendo diversos países emergentes exitosos en este campo, entre ellos India y Brasil. Es tal vez por ausencia de esta capacidad para poner en práctica políticas ad-hoc que el país se alejó tanto, a partir de los años setenta, de los países del Este asiático, y a partir por lo menos de inicios del siglo XXI del grupo de naciones conocido como BRIC: Brasil, Rusia, India y China.

Aunque la teoría del comercio internacional enfatiza que, a nivel macroeconómico, la integración económica favorece a los países que optan por coludirse en el marco genérico de lo que se conoce como uniones aduaneras (desmantelamiento arancelario, acuerdos de integración, tratados de libre comercio, etcétera), también reconoce, como ya se vio, que a nivel microeconómico dicho esquema produce ganadores y perdedores. El presente trabajo ha demostrado, con ayuda de una poderosa herramienta, el software TradeCAN de la CEPAL, 
que éste es el caso de la industria farmacéutica en el ámbito del TLCAN, donde después de 16 años de operación se han establecido dos ganadores evidentes, Estados Unidos y Canadá, y un perdedor, México.

De la misma manera, la teoría establece que, cuando las diferencias de desarrollo son muy claras entre las naciones que se integran, habrá una tendencia natural a que la mayor parte de los beneficios de la integración fluya hacia los países con mayor nivel de desarrollo.

Aunque las dos premisas anteriores las conocían los negociadores mexicanos del TLCAN, decidieron tomar el riesgo porque concibieron, como lo evidencian los documentos oficiales previos a la firma del Tratado, un México orientado a la especialización, en el que si algunas industrias declinaban, lo mismo en producción que en empleo, otras las superarían con creces, de tal manera que, en términos generales, el país se volvería más competitivo, crecería más aceleradamente y generaría un mayor número de empleos.

Desafortunadamente lo anterior no se ha dado en la práctica y sí, por el contrario, muchas industrias han sido arrastradas hasta la virtual quiebra, desde la de juguetes, zapatera, mueblera, y textil y de la confección, hasta la farmacéutica, que no sólo dejó de ser fuente de innovación tecnológica, sino que se tornó deficitaria y, dado el número de fabricantes extranjeros, perdió su vinculación con los objetivos de desarrollo del país, particularmente el de apoyar la salud de los mexicanos.

Los resultados del análisis TradeCAN muestran que la recomposición regional anterior, con dos ganadores grandes y un perdedor pequeño, no ha sido suficiente para posicionar la región del TLCAN como la más competitiva en el ámbito internacional, aunque Estados Unidos sigue dando muestra de ser el país con mayor cuota de mercado del mundo. En este sentido, quizá la mejor estrategia de dicho país sería promover cadenas productivas regionales, establecer laboratorios y centros de investigación en materia farmacéutica y buscar el apoyo de Canadá para que en esta industria, como en la automotriz, los recursos fluyan un poco hacia el sur.

Es sintomático que, a pesar de que el virus de la influenza humana AH1N1 surgió casi con toda seguridad en la frontera entre Estados Unidos y México y correspondió a un laboratorio canadiense su aislamiento, las primeras vacunas no fueron resultado de la integración en materia científica y tecnológica de laboratorios establecidos en los tres o en dos países de la región, sino que surgieron en Suiza (Novartis), Reino Unido (GlaxoSmithKline) y Estados Unidos (Baxter). Evidentemente para lograr dicha integración se requiere invertir previamente en 
capital humano; pero tampoco conviene continuar dejando desprotegida a esta industria, en la que México ya se había labrado un espacio, previo a la aceptación de los ADPIC y la firma del TLCAN, como quedó evidenciado en la primera parte de este documento.

Sin necesidad de grandes investigaciones, es un hecho que, como lo demuestra la historia de la ciencia y la tecnológica, en México las industrias química y farmacéutica han tenido un papel importante, sobre todo por su vinculación con la minería y otras actividades fundamentales de la economía colonial, y por el ritmo acelerado de crecimiento de la población durante 1960-1990. Sobre estas bases aquí se descubrió, hace poco más de dos siglos, uno de los elementos químicos, el vanadio, y se desarrolló, hace medio siglo, la píldora anticonceptiva. Posteriormente, y gracias a la colaboración científica entre mexicanos y estadounidenses, un científico de nuestro país se hizo acreedor, en 1995, al Premio Nobel de química por haber descubierto las consecuencias de la contaminación ambiental en la destrucción de la capa de ozono. Estos hechos sugieren que México tiene experiencia y capital humano para participar, junto con Estados Unidos y Canadá, en un proceso de apoyo a la consolidación regional de la industria químico farmacéutica, proceso que, por el bien de América del Norte, debería reproducirse en otras industrias. 


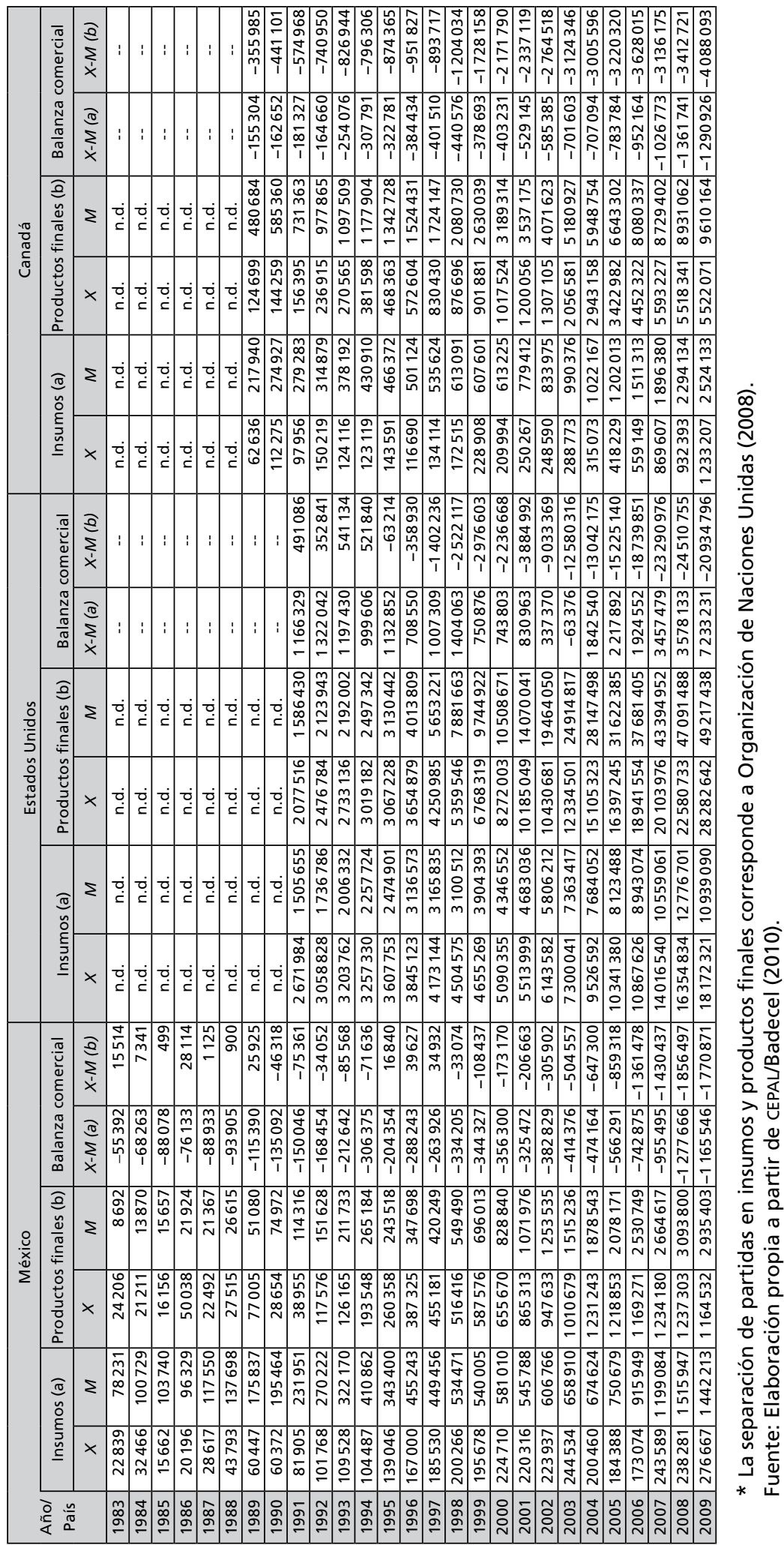




\section{REFERENCIAS BIBLIOGRÁFICAS}

Aboites, Jaime (2005), "Cambio institucional internacional de los derechos de propiedad intelectual”, en Guzmán y Viniegra (2005a).

_ y Manuel Soria (2008), Economía del conocimiento y propiedad intelectual. Lecciones para la economía mexicana, México, UAM/Siglo XXI Editores.

et al. (eds.) (2003), Innovación, aprendizaje y creación de capacidades tecnológicas, Miguel Ángel Porrúa-UAM Xochimilco, México.

AMIIF (2010), en www.amiif.org.mx (consultado durante 2010 y 2011).

Banxico (2011), Balanza de pagos de México, en www.banxico.org.mx

Borrel Arqué, Joan-Ramón (2004), “¿Las patentes aceleran o retrasan la comercialización de nuevos medicamentos en los países en desarrollo?", Cuadernos Económicos, ICE, ISSN 0210-2633, Universidad de Barcelona.

Brown y Guzmán, (2004), “Diseminación tecnológica en la industria Farmacéutica mexicana", Comercio exterior, Vol. 54, No. 11, noviembre, México.

CEPAL (1995), La industria farmacéutica y farmoquímica mexicana en el marco regulatorio de los años noventa, LC/R 1540, Santiago de Chile, 12 de julio.

(1999), La industria farmacéutica y farmoquímica en México y el Distrito $\mathrm{Fe}$ deral, México.

(2008), "Consecuencias para los productos farmacéuticos", en América Latina y el Caribe: La propiedad intelectual después de los tratados de libre comercio, Santiago de Chile, CEPAL, Libro de la CEPAL, núm. 94.

— Badecel (2010), Estadísticas, en www.cepal.org (consultado durante 2010 y 2011).

Corona, Juan Manuel, y María del Carmen Jiménez (2003), “Trayectoria científico-tecnológica en la industria farmacéutica”, en Aboites (2003).

Correa, Carlos María (1990), Patentes industria farmacéutica y biotecnología, síntesis de la presentación en el Foro Latinoamericano de Industria Farmacéutica, Guatemala, abril.

(2002), Protección de los datos presentados para el Registro de Productos Farmacéuticos. Implementación de las Normas del Acuerdo ADPIC, Centro del Sur, diciembre.

(2004), Protecting Test Data for Pharmaceutical and Agrochemical Products Under Free Trade Agreements, Universidad de Buenos Aires, UNCTAD-ICTSD Dialogue on Moving the pro-development IP agenda forward: Preserving Public Goods in Health, Education and Learning, Bellagio, 29 de noviembre3 diciembre. 
Correa, Carlos María (2005a), "Propiedad intelectual, políticas farmacéuticas y medicamentos esenciales. Repercusiones de la declaración de Doha relativa al acuerdo sobre los Aspectos de los Derechos de Propiedad Intelectual relacionados con el Comercio (ADPIC) y la salud pública", Revista de la Maestría en Salud Pública, año 3, núm 5, agosto, Universidad de Buenos Aires.

— (2005b), "Patentes y competencia en el mercado farmacéutico", en Guzmán y Viniegra (2005a).

- (2006), "La rueda de Doha: Expectativas y frustraciones de los países en desarrollo", Universidad de Buenos Aires, octubre 30.

- (2007), "Guidelines for the examination of pharmaceutical patents: Developing a public health perspective", Universidad de Buenos Aires, WHO-ICTSD-UNCTAD, enero.

Danzon, Patricia M., y Michael F. Farukawa (2003), "Prices and Availability of Pharmaceuticals: Evidence from Nine Countries", Health Affairs, 29 de octubre.

Diario Oficial de la Federación (DOF) (1991), "Nueva Ley de la Propiedad Industrial", 27 de junio.

Gonsen, R., y J. Jasso (2000) "La industria farmacéutica y el sistema de innovación sectorial", El mercado de valores, febrero, pp. 36-43.

Guerrero Castro, Rodrigo A. (2010), Consecuencias para la industria farmacéutica mexicana de la aplicación de los ADPIC, asociados a la firma del TLCAN, en la estructura del comercio exterior y en la producción de conocimiento patentado, documento graduatorio, Maestría en Economía y Gestión de la Innovación, UAM-Xochimilco, México.

Gutiérrez R., Roberto (2007), La hipótesis de Linder, la nueva teoría del comercio internacional y el comercio intraindustrial Norte-Sur: El caso de las economías emergentes manufactureras, Departamento de Economía, UAM-I, tesis doctoral.

Guzmán, Alenka G., et al. (2004), "Brechas tecnológicas y de innovación entre países industrializados y países en desarrollo en la industria farmacéutica”, Investigación Económica, Vol. LXIII, núm. 248, abril-junio.

y Flor Brown (2004), “Diseminación tecnológica en la industria farmacéutica mexicana", Comercio Exterior, Vol. 54, núm. 11, noviembre.

— y María Pluvia Zúñiga (2004). "Patentes en la industria farmacéutica de México: Los efectos en la investigación”, Comercio Exterior, Vol. 54, núm. 12, diciembre.

y Gustavo Viniegra (2005a) (coords.), Industria farmacéutica y propiedad intelectual: los países en desarrollo, México, UAM/Miguel Ángel Porrúa/Cámara de Diputados. 
Guzmán, Alenka G., y Gustavo Viniegra (2005b), "Naturaleza de la ID y las patentes de la industria farmacéutica en México”, en Guzmán y Viniegra (2005a).

INEGI (2011), PIB, tipo de cambio y otras series históricas, en www.inegi.org.mx (consultado durante 2010 y 2011).

Intermon Oxfam (2001), "Empresas farmacéuticas versus Brasil: Una amenaza para la salud pública”, Fundación para el Tercer Mundo, en http://www.intermonoxfam. org/cms/HTML/espanol/454/ADPIC_BrasilEmpresas.pdf (consultado en septiembre de 2010).

Krazov-Jinich (2003), en Moïse y Docteur (2007).

Linder, Staffan Burenstam (1961), An Essay on Trade and Transformation, Estocolmo, Almqvist \& Wicksell.

Mansfield, Edwin (1986), "Patents and Innovation: An Empirical Study", Management Science, Vol. 32, núm. 2, febrero.

Martínez, Jorge Mario (coord.) (2008a), Generación y protección del conocimiento: propiedad intelectual, innovación y desarrollo económico, México, CEPAL, Sede Subregional.

- (2008 b), "La protección de los derechos de propiedad intelectual, la innovación y el desarrollo", en Martínez (2008a).

Michaely, Michael (1962), Concentration in International Trade, Ámsterdam, North Holland.

Moïse, Pierre, y Elizabeth Docteur (2007), "Pharmaceutical Pricing and Reimbursement Policies in Mexico", OECD Health Working Papers núm. 25, en http://www. oecd.org/dataoecd/39/36/38097348.pdf (consultado en septiembre de 2010).

Nieto, Fabiola (2010), "David contra Goliat", Revista Fortuna, en http://revistafortuna. com.mx/opciones/archivo/2005/noviembre/htm/david_vs_goliat.htm (consultado en octubre de 2011).

OECD (2002), "Intra-Industry and Intra-Firm Trade and the Internationalisation of Production", OECD Economic Outlook 2002, París.

- (2009), Manual de estadísticas de patentes de la OECD, París.

Organización de Naciones Unidas (2008), Clasificación Uniforme para el Comercio Internacional. Revisión 4, Nueva York.

Ortún V. (2004), "Patentes, regulación de precios e innovación en la industria farmacéutica", Cuadernos económicos de I.C.E. núm. 67, Centro de Investigación en Economía y Salud, Universidad Pompeu Fabra, Barcelona, en http://www.econ. upf.edu/ ortun/publicacions/ICEPatent.pdf (consultado en septiembre de 2010). PNUD (2003), Cómo lograr que el comercio global sea beneficioso para la gente, Nueva York, Ed. Eesthscan. 
Roffe, Pedro (2008), "La propiedad intelectual y la nueva generación de acuerdos de libre comercio: El tratado entre Chile y Estados Unidos de Norteamérica", en Martínez (2008a).

Salvatore, Dominick (2005), Economía internacional, México, $8^{\mathrm{a}}$ ed., Limusa Wiley.

Shiva, Vandala (2003), ¿Proteger o expoliar? Los derechos de propiedad intelectual, Intermón Oxfam, Colección Libros de Encuentro.

Tradecan (2009), Software en disco y guía de usuario, CEPAL, Santiago.

Trens Flores, Ernesto (2000), "El desarrollo tecnológico y las políticas de salud", Revista de la Facultad de Medicina, UNAM, Vol. 43, núm.1, enero-febrero. 